\title{
Assessment of highly polar chemicals in Dutch and Flemish drinking water and its sources: presence and potential risks
}

Annemieke Kolkman ${ }^{1,}$, Dennis Vughs ${ }^{1}$, Rosa Sjerps ${ }^{1, \$}$, Pascal J.F. Kooij ${ }^{1}$, Margo van der Kooi ${ }^{1}$, Kirsten Baken ${ }^{1, \$}$, Jochem Louisse ${ }^{1, \$}$, Pim de Voogt ${ }^{1,2,{ }^{*}}$

1 KWR Watercycle Research Institute, P.O. Box 1072, 3430 BB Nieuwegein, The Netherlands

2 Institute for Biodiversity and Ecosystem Dynamics, University of Amsterdam, P.O. Box 94248, Amsterdam, Netherlands

* Corresponding author at: KWR Watercycle Research Institute, P.O. Box 1072, 3430 BB Nieuwegein, The Netherlands. Tel.: +31 03060 69655; fax: +310306061 165.- pim.de.voogt@kwrwater.nl

\section{Supporting information}

- $\quad$ Table S1. Method performance characteristics for HILIC-MS screening method for 32 highly polar compounds in drinking and surface water

- $\quad$ Figure S1. Chromatograms of the standards used for target analysis

- Table S2. Pearson product moment correlation coefficients of concentrations of melamine, melem, melam and cyanuric acid observed in water samples

- $\quad$ Figure S2. Workflow used in non-target mass spectrometry screening

- Table S3. Characteristics of the compounds identified in non-target screening

- $\quad$ Figures S3-S14: Chromatographic and mass spectrometric confirmation of identity of unknown compounds with a reference standard:

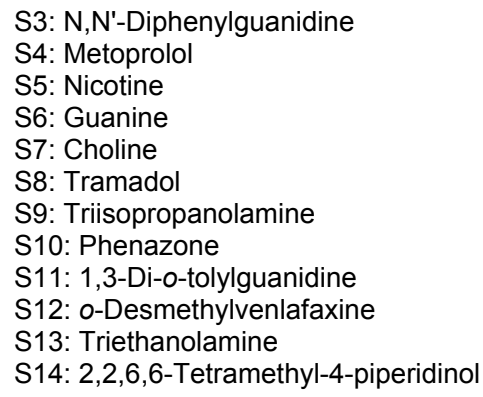

- Summary of data processing parameters and Compound Discoverer 2.1 settings

\footnotetext{
$\S$ Current addresses: AK: The Royal Dutch Pharmacists Association (KNMP), Alexanderstraat 11, $2514 \mathrm{JL}$, The Haque, The Netherlands, RS: Oasen Drinking Water Company, P.O. Box 122, 2800 AC Gouda, The Netherlands; KB: : Unit Health, Flemish Institute for Technological Research (VITO NV), Boeretang 200, 2400 Mol, Belgium; JL: Wageningen Food Safety Research, Akkermaalsbos 2, 6708 WB Wageningen, The Netherlands.
} 
Table S1. Method performance characteristics for HILIC-MS screening method for 32 highly polar compounds in drinking and surface water

\begin{tabular}{|c|c|c|c|c|c|c|c|c|c|c|c|c|c|c|}
\hline \multirow[b]{2}{*}{ Compound } & \multirow[b]{2}{*}{$\begin{array}{l}\log \mathrm{D} \\
\text { at } \\
\mathrm{pH} 7.4^{\mathrm{a}}\end{array}$} & \multirow[b]{2}{*}{$\begin{array}{l}\text { Ionisation } \\
\text { mode }\end{array}$} & \multirow[b]{2}{*}{ Ion } & \multirow[b]{2}{*}{$\begin{array}{c}\text { Accurate } \\
\text { Mass } \\
(\mathrm{m} / \mathrm{z})\end{array}$} & \multirow[b]{2}{*}{$\begin{array}{c}\text { MS/MS } \\
\text { Fragment } \\
\text { Ion } \\
(\mathrm{m} / \mathrm{z})\end{array}$} & \multirow[b]{2}{*}{$\begin{array}{c}t_{R} \\
(\mathrm{~min})\end{array}$} & \multicolumn{4}{|c|}{ Drinking water } & \multicolumn{4}{|c|}{ Surface Water } \\
\hline & & & & & & & $\begin{array}{l}\text { LOD } \\
(\mu \mathrm{g} / \mathrm{L})\end{array}$ & $\mathrm{LOQ}(\mu \mathrm{g} / \mathrm{L})$ & $\begin{array}{c}\text { RSD } \\
1 \mu \mathrm{g} / \mathrm{L}(\%) \\
(\mathrm{n}=8)\end{array}$ & $\begin{array}{c}\text { Recovery } \\
1 \mu \mathrm{g} / \mathrm{L} \\
(\%) \\
(\mathrm{n}=8)\end{array}$ & $\begin{array}{l}\mathrm{LOD} \\
(\mu \mathrm{g} / \mathrm{L})\end{array}$ & $\begin{array}{l}\mathrm{LOQ} \\
(\mu \mathrm{g} / \mathrm{L})\end{array}$ & $\begin{array}{c}\text { RSD } \\
1 \mu \mathrm{g} / \mathrm{L}(\%) \\
(\mathrm{n}=8)\end{array}$ & $\begin{array}{c}\text { Recovery } \\
1 \mu \mathrm{g} / \mathrm{L}(\%) \\
(\mathrm{n}=8)\end{array}$ \\
\hline 5-Fluorocystosine & -2.16 & pos & {$[\mathrm{M}+\mathrm{H}]^{+}$} & 130.04112 & 113.01457 & 5.13 & 0.003 & 0.008 & 7.2 & 102.9 & 0.002 & 0.006 & 3.8 & 84.5 \\
\hline Acephate & -0.53 & pos & {$[\mathrm{M}+\mathrm{H}]^{+}$} & 184.01918 & 142.99263 & 2.10 & 0.20 & 0.59 & 6.8 & 93.1 & 0.16 & 0.47 & 8.2 & 62.1 \\
\hline Ammelide & -4.29 & pos & {$[\mathrm{M}+\mathrm{H}]^{+}$} & 129.04070 & 87.01890 & 3.66 & 0.028 & 0.085 & 14.1 & 58.7 & 0.009 & 0.026 & 11.0 & 14.5 \\
\hline Ammeline & -2.76 & pos & {$[\mathrm{M}+\mathrm{H}]^{+}$} & 128.05669 & 86.03489 & 7.01 & 0.012 & 0.036 & 7.7 & 97.1 & 0.019 & 0.056 & 5.3 & 114.6 \\
\hline Amprolium & -2.86 & pos & {$[\mathrm{M}]^{+}$} & 243.16042 & 150.10257 & 10.70 & 0.018 & 0.053 & 11.8 & 85.3 & 0.084 & 0.25 & 3.9 & 89.0 \\
\hline Chlormequat & -3.04 & pos & {$[\mathrm{M}]^{+}$} & 122.07310 & 58.06513 & 8.80 & 0.005 & 0.016 & 8.5 & 102.7 & 0.005 & 0.014 & 9.7 & 105.1 \\
\hline Chlormequat-d $($ ISTD) & - & pos & {$[\mathrm{M}]^{+}$} & 131.12959 & - & 8.80 & - & - & - & - & - & - & - & - \\
\hline Cotinine & 0.17 & pos & {$[\mathrm{M}+\mathrm{H}]^{+}$} & 177.10224 & 80.04948 & 4.32 & 0.003 & 0.010 & 7.0 & 109.4 & 0.003 & 0.009 & 10.9 & 77.1 \\
\hline Cyromazin & 0.23 & pos & {$[\mathrm{M}+\mathrm{H}]^{+}$} & 167.10397 & 85.05087 & 5.71 & 0.004 & 0.011 & 3.2 & 107.5 & 0.002 & 0.005 & 3.2 & 107.8 \\
\hline Cytarabine & -2.18 & pos & {$[\mathrm{M}+\mathrm{H}]^{+}$} & 244.09280 & 112.05054 & 6.56 & 0.024 & 0.071 & 9.4 & 93.0 & 0.088 & 0.26 & 5.3 & 107.7 \\
\hline Diatrizoic acid & -1.00 & pos & {$[\mathrm{M}+\mathrm{H}]^{+}$} & 614.77690 & 233.05568 & 7.10 & 0.087 & 0.26 & 13.8 & 114.5 & 0.093 & 0.28 & 8.9 & 99.7 \\
\hline Gabapentin & -1.40 & pos & {$[\mathrm{M}+\mathrm{H}]^{+}$} & 172.13321 & 154.12264 & 8.81 & 0.01 & 0.031 & 6.0 & 99.4 & 0.087 & 0.26 & 7.8 & 97.2 \\
\hline Gemcitabine & -1.36 & pos & {$[\mathrm{M}+\mathrm{H}]^{+}$} & 264.07904 & 112.05054 & 3.08 & 0.003 & 0.008 & 7.1 & 108.7 & 0.007 & 0.021 & 5.6 & 22.1 \\
\hline Guanylurea & -1.82 & pos & {$[\mathrm{M}+\mathrm{H}]^{+}$} & 103.06144 & 60.05562 & 7.30 & 0.022 & 0.067 & 6.0 & 85.4 & 0.12 & 0.35 & 2.9 & 112.0 \\
\hline lohexol & -3.17 & pos & {$[\mathrm{M}+\mathrm{H}]^{+}$} & 821.88761 & 803.87702 & 7.10 & 0.24 & 0.73 & 7.7 & 104.5 & 0.20 & 0.61 & 6.3 & 101.2 \\
\hline lopamidol & -2.31 & pos & {$[\mathrm{M}+\mathrm{H}]^{+}$} & 777.86140 & 558.88575 & 4.70 & 0.082 & 0.25 & 7.0 & 88.5 & 0.11 & 0.33 & 9.4 & 92.6 \\
\hline Iopromide & -2.12 & pos & {$[\mathrm{M}+\mathrm{H}]^{+}$} & 791.87705 & 572.90140 & 4.75 & 0.046 & 0.14 & 9.4 & 102.2 & 0.11 & 0.33 & 8.8 & 88.1 \\
\hline Maleic hydrazide & -3.06 & pos & {$[\mathrm{M}+\mathrm{H}]^{+}$} & 113.03455 & 85.03964 & 2.66 & 0.13 & 0.40 & 27.0 & 16.2 & 0.071 & 0.50 & 6.0 & 38.0 \\
\hline Melam & -2.15 & pos & $\begin{array}{c}0.15[\mathrm{M} \\
+\mathrm{H}]^{+}\end{array}$ & 236.11152 & 152.06792 & 8.19 & 0.002 & 0.006 & 13.1 & 101.6 & 0.003 & 0.009 & 8.4 & 90.6 \\
\hline Melamine & -1.18 & pos & {$[\mathrm{M}+\mathrm{H}]^{+}$} & 127.07267 & 85.05087 & 6.38 & 0.19 & 0.57 & 4.7 & 118.5 & 0.19 & 0.56 & 3.0 & 96.4 \\
\hline Melem & -4.18 & pos & {$[\mathrm{M}+\mathrm{H}]^{+}$} & 219.08497 & 177.06317 & 6.16 & 0.023 & 0.068 & 10.2 & 97.4 & 0.020 & 0.061 & 15.6 & 97.8 \\
\hline Mepiquat & -2.34 & pos & {$[\mathrm{M}]^{+}$} & 114.12773 & 98.09643 & 10.05 & 0.006 & 0.019 & 9.6 & 116.8 & 0.007 & 0.022 & 7.3 & 92.5 \\
\hline Metformin & -3.36 & pos & {$[\mathrm{M}+\mathrm{H}]^{+}$} & 130.10872 & 71.06037 & 8.60 & 0.004 & 0.011 & 8.4 & 104.0 & 0.24 & 0.71 & 7.5 & 92.8 \\
\hline Methamidophos & -0.56 & pos & {$[\mathrm{M}+\mathrm{H}]^{+}$} & 142.00862 & 112.01581 & 2.13 & 0.072 & 0.22 & 7.5 & 114.2 & 0.098 & 0.29 & 8.0 & 99.0 \\
\hline Niacin & -2.60 & pos & {$[\mathrm{M}+\mathrm{H}]^{+}$} & 124.03930 & 80.04948 & 5.67 & 0.009 & 0.027 & 6.5 & 101.8 & 0.006 & 0.019 & 6.9 & 104.2 \\
\hline N-Methyldiethanolamine & -1.79 & pos & {$[\mathrm{M}+\mathrm{H}]^{+}$} & 120.10191 & 102.09134 & 9.50 & 0.027 & 0.080 & 9.7 & 95.2 & 0.020 & 0.059 & 8.0 & 97.9 \\
\hline Omethoate & -0.84 & pos & {$[\mathrm{M}+\mathrm{H}]^{+}$} & 214.02974 & 142.99263 & 2.17 & 0.013 & 0.040 & 8.4 & 91.9 & 0.010 & 0.029 & 8.3 & 101.4 \\
\hline Sotalol-d $\mathrm{d}_{7}$ (ISTD) & - & pos & {$[\mathrm{M}+\mathrm{H}]^{+}$} & 280.17068 & - & 7.50 & - & - & - & - & - & - & - & - \\
\hline Tetrapropylammonium (TPA) & -1.77 & pos & {$[\mathrm{M}+\mathrm{H}]^{+}$} & 186.22218 & 114.12773 & 7.19 & 0.006 & 0.018 & 10.1 & 100.9 & 0.008 & 0.023 & 2.2 & 107.4 \\
\hline Urotropin (Hexamine) & 0.99 & pos & {$[\mathrm{M}+\mathrm{H}]^{+}$} & 141.11347 & 112.08692 & 11.30 & 0.04 & 0.12 & 11.0 & 116.8 & 0.45 & 1.3 & 3.4 & 141.8 \\
\hline 5-Fluorouracil & -1.57 & neg & {$[\mathrm{M}-\mathrm{H}]^{-}$} & 129.01058 & 58.99387 & 1.81 & 0.008 & 0.025 & 4.0 & 110.7 & 0.014 & 0.041 & 6.3 & 108.4 \\
\hline
\end{tabular}




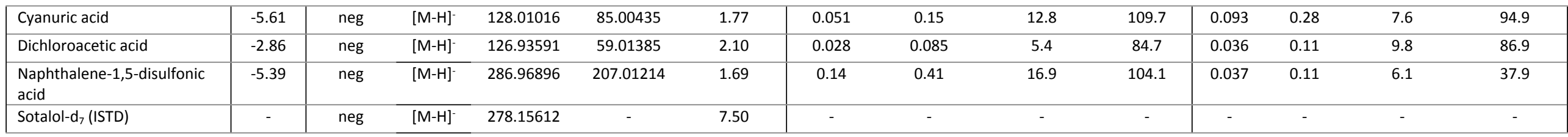

a Log D predicted by ACD/Labs platform (taken from ChemSpider)

\section{Flgure S1. Chromatograms of the standards used for target analysis}

Extracted ion chromatogram of a standard $(1 \mu \mathrm{g} / \mathrm{L})$ containing all target compounds in positive mode.

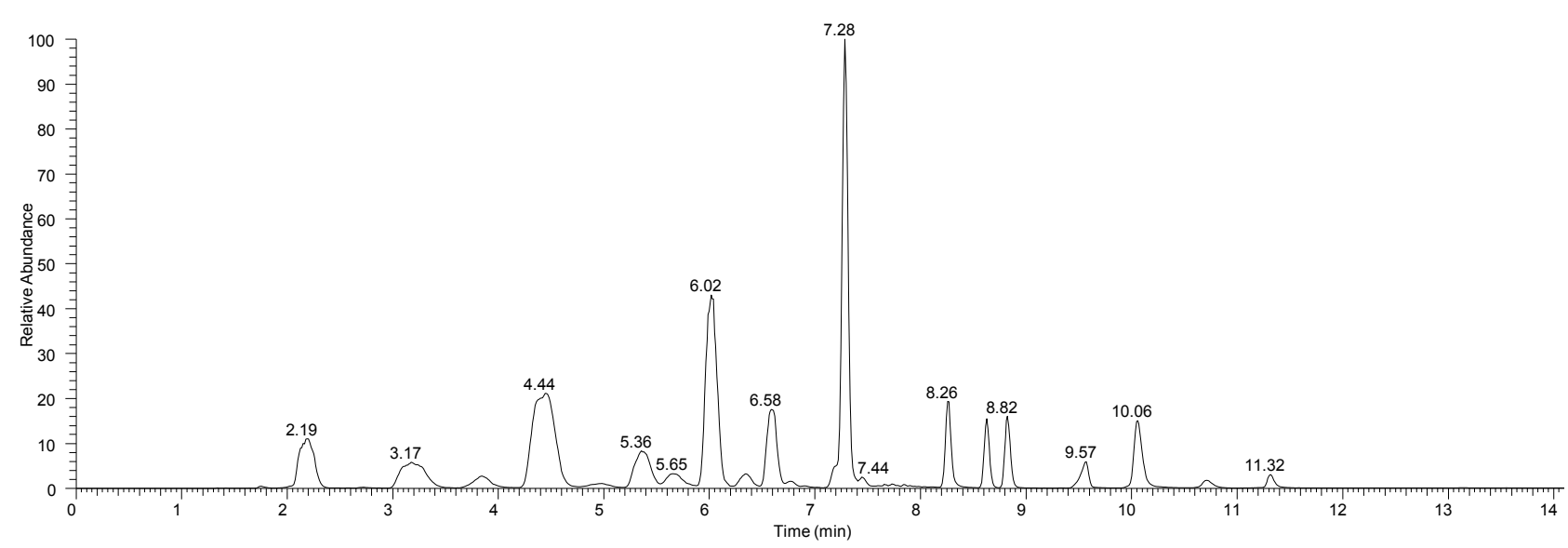

Extracted ion chromatogram of a standard $(1 \mu \mathrm{g} / \mathrm{L})$ containing all target compounds in negative mode

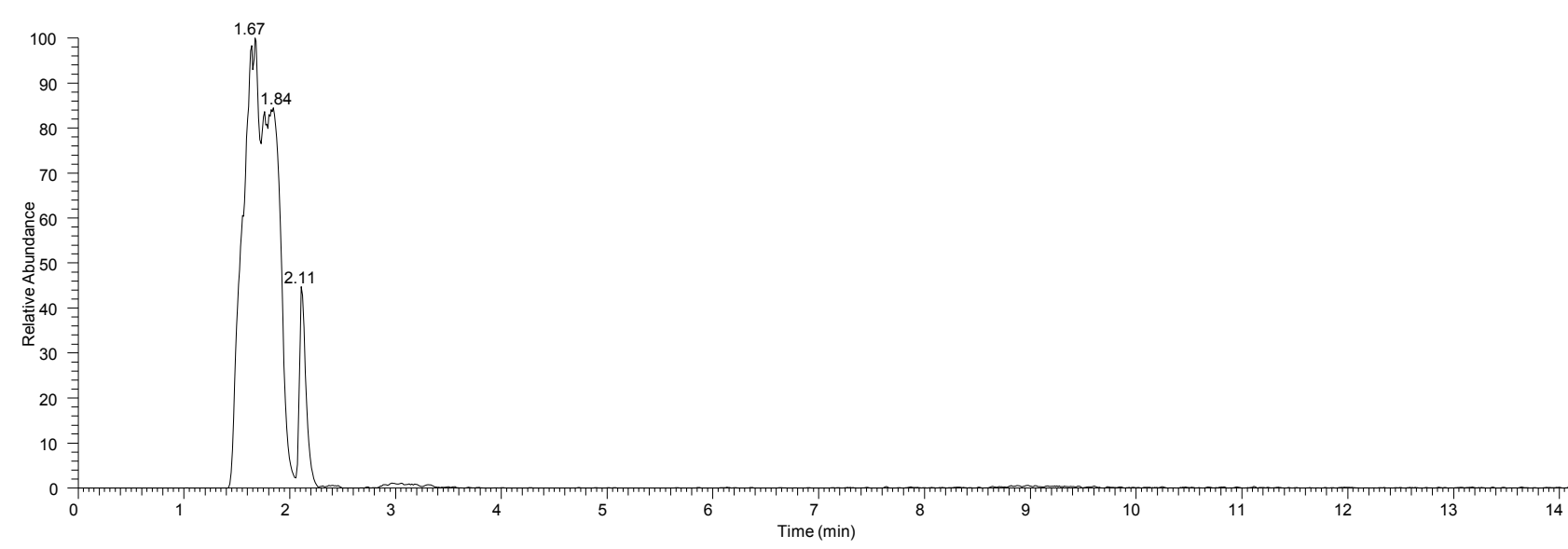


Table S2. Pearson product moment correlation coefficients of concentrations of melamine, melem, melam and cyanuric acid observed in water samples $(n=24)$

(when values below LOD or between LOD and LOQ were measured, a value of $0.5 x L O D$ or $0.5 x L O Q$, respectively, was used)

\begin{tabular}{llcc}
\hline \multicolumn{2}{c}{ Relationship } & Pearson $\mathbf{r}$ & p value \\
\hline Melamine & Melem & 0.48 & 0.017 \\
Melamine & Melam & 0.45 & 0.027 \\
Melamine & Cyanuric acid & 0.74 & $<0.01$ \\
Melem & Melam & 0.98 & $<0.01$ \\
Melem & Cyanuric acid & 0.83 & $<0.01$ \\
Melam & Cyanuric acid & 0.78 & $<0.01$ \\
\hline
\end{tabular}

Concentration data $(\mu \mathrm{g} / \mathrm{L})$ used for calculation of Pearson product moment correlation coefficients (for compounds detected between LOQ and LOD a value of $0.5 x$ LOQ was used (indicated by ${ }^{* *}$ ), for compounds not detected in a sample, a value of $0.5 \times L O D$ was used, indicated by*). Note that LOD/LOQs may differ between surface water and tapwater (for LODs/LOQs see Table S1)

\begin{tabular}{|c|c|c|c|}
\hline Melamine & Melem & Melam & Cyanuric acid \\
\hline 3.49 & $0.010^{*}$ & $0.002^{*}$ & $0.14^{* *}$ \\
\hline 2.79 & 0.127 & 0.020 & 0.48 \\
\hline 2.18 & 0.081 & 0.011 & 0.33 \\
\hline 1.93 & $0.010^{*}$ & $0.002^{*}$ & $0.14^{* *}$ \\
\hline 1.91 & $0.010^{*}$ & $0.002^{*}$ & $0.14^{* *}$ \\
\hline 1.88 & $0.012^{*}$ & $0.001^{*}$ & 0.24 \\
\hline 1.49 & 0.146 & $0.030^{*}$ & 0.30 \\
\hline 0.70 & $0.012^{*}$ & $0.001^{*}$ & $0.03^{*}$ \\
\hline $0.10^{*}$ & $0.012^{*}$ & $0.001^{*}$ & $0.14^{* *}$ \\
\hline $0.10^{*}$ & $0.010^{*}$ & $0.002^{*}$ & $0.08^{*}$ \\
\hline $0.10^{*}$ & $0.012^{*}$ & $0.001^{*}$ & $0.03^{*}$ \\
\hline $0.10^{*}$ & $0.012^{*}$ & $0.001^{*}$ & $0.03^{*}$ \\
\hline $0.10^{*}$ & $0.012^{*}$ & $0.001^{*}$ & $0.03^{*}$ \\
\hline $0.10^{*}$ & $0.012^{*}$ & $0.001^{*}$ & $0.03^{*}$ \\
\hline $0.10^{*}$ & $0.010^{*}$ & $0.002^{*}$ & $0.08^{*}$ \\
\hline $0.10^{*}$ & $0.012^{*}$ & $0.001^{*}$ & $0.03^{*}$ \\
\hline $0.10^{*}$ & $0.010^{*}$ & $0.002^{*}$ & $0.08^{*}$ \\
\hline $0.10^{*}$ & $0.012^{*}$ & $0.001^{*}$ & $0.03^{*}$ \\
\hline $0.10^{*}$ & $0.012^{*}$ & $0.001^{*}$ & $0.03^{*}$ \\
\hline $0.10^{*}$ & $0.010^{*}$ & $0.002^{*}$ & $0.08^{*}$ \\
\hline $0.10^{*}$ & $0.012^{*}$ & $0.001^{*}$ & $0.03^{*}$ \\
\hline $0.10^{*}$ & $0.010^{*}$ & $0.002^{*}$ & $0.08^{*}$ \\
\hline $0.10^{*}$ & $0.012^{*}$ & $0.001^{*}$ & $0.03^{*}$ \\
\hline $0.10^{*}$ & $0.010^{*}$ & $0.002^{*}$ & $0.08^{*}$ \\
\hline
\end{tabular}


Figure S2. Workflow used in non-target mass spectrometry screening

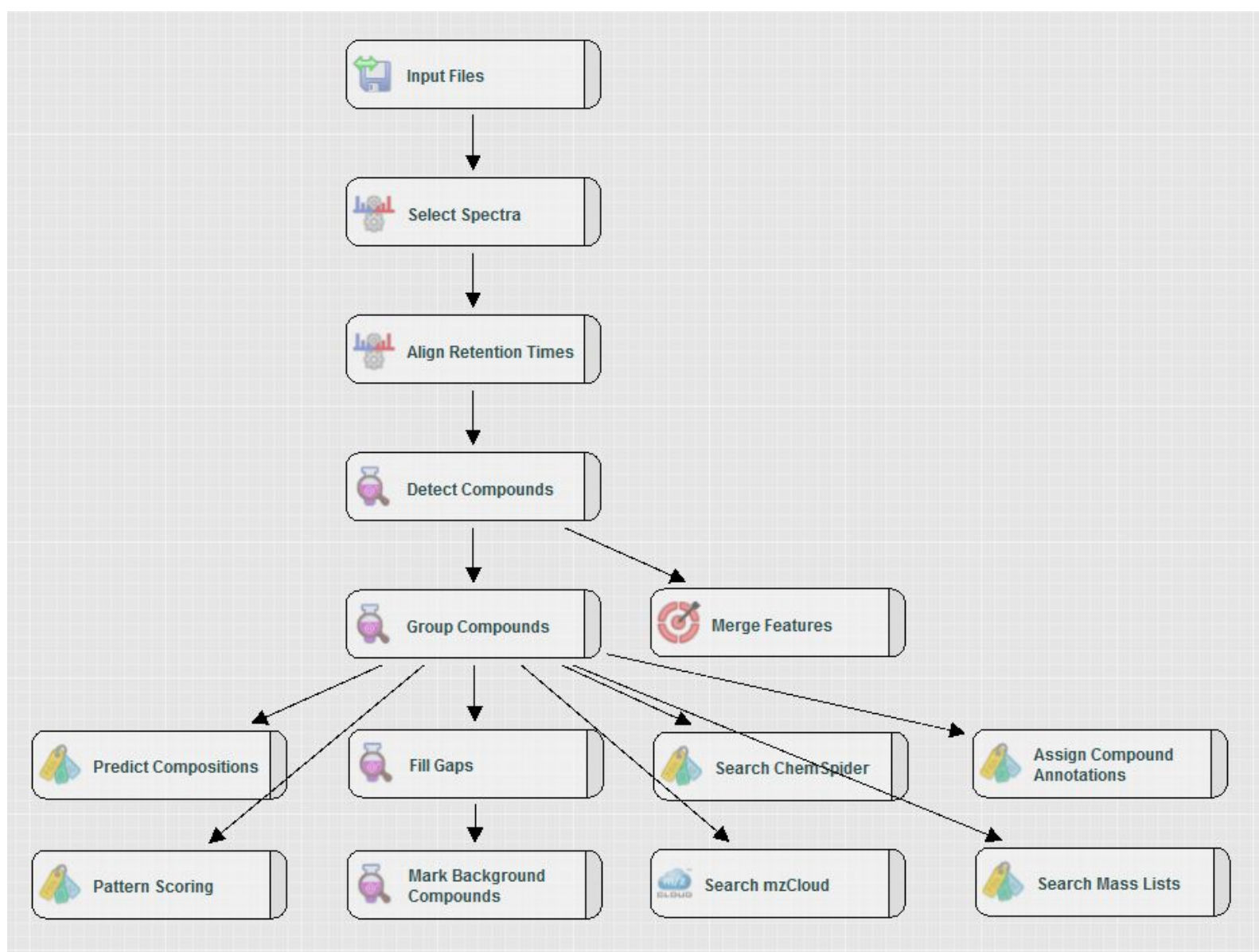


Table S3. Characteristics of the compounds identified in non-target screening

\begin{tabular}{|c|c|c|c|c|c|}
\hline Compound & $\begin{array}{c}\log D \\
\text { at } \\
\mathrm{pH} 7.4^{\mathrm{a}}\end{array}$ & $\begin{array}{l}\text { Ionisation } \\
\text { mode }\end{array}$ & Ion & $\begin{array}{l}\text { Accurate } \\
\text { mass }\end{array}$ & $\begin{array}{c}t_{R} \\
(\min )\end{array}$ \\
\hline $\mathrm{N}, \mathrm{N}$-diphenylguanidine & -0.41 & pos & {$[\mathrm{M}+\mathrm{H}]^{+}$} & 212.11822 & 6.48 \\
\hline Metoprolol & -0.25 & pos & {$[\mathrm{M}+\mathrm{H}]^{+}$} & 268.19072 & 7.24 \\
\hline (-)-Nicotine & -0.37 & pos & {$[\mathrm{M}+\mathrm{H}]^{+}$} & 163.12298 & 10.07 \\
\hline Guanine & -0.68 & pos & {$[\mathrm{M}+\mathrm{H}]^{+}$} & 152.05669 & 5.87 \\
\hline Choline & -3.79 & pos & {$[\mathrm{M}+\mathrm{H}]^{+}$} & 104.10699 & 9.94 \\
\hline Tramadol & 0.52 & pos & {$[\mathrm{M}+\mathrm{H}]^{+}$} & 264.19581 & 7.21 \\
\hline Triisopropanolamine & -1.19 & pos & {$[\mathrm{M}+\mathrm{H}]^{+}$} & 192.15942 & 8.34 \\
\hline Phenazone & 0.72 & pos & {$[\mathrm{M}+\mathrm{H}]^{+}$} & 189.10224 & 2.68 \\
\hline 1,3-di-o-tolylguanidine & 2.31 & pos & {$[\mathrm{M}+\mathrm{H}]^{+}$} & 240.14952 & 6.40 \\
\hline O-desmethylvenlafaxine & 0.89 & pos & {$[\mathrm{M}+\mathrm{H}]^{+}$} & 264.19581 & 7.64 \\
\hline Triethanolamine & -1.65 & pos & {$[\mathrm{M}+\mathrm{H}]^{+}$} & 150.11247 & 9.40 \\
\hline $\begin{array}{l}\text { 2,2,6,6-tetramethyl-4- } \\
\text { piperidinol }\end{array}$ & -1.11 & pos & {$[\mathrm{M}+\mathrm{H}]^{+}$} & 158.15394 & 8.27 \\
\hline
\end{tabular}

a Log D predicted by ACD/Labs platform (taken from ChemSpider) 
Figures S3-S14: Chromatographic and mass spectrometric confirmation of identity of unknown compounds with a reference standard

Figure S3: Confirmation of the identity of N,N'-diphenylguanidine

Extracted ion chromatogram ( $\mathrm{m} / \mathrm{z} 212.1182$ ) of sample (upper panel) and reference standard (lower panel) of N,N'diphenylguanidine:

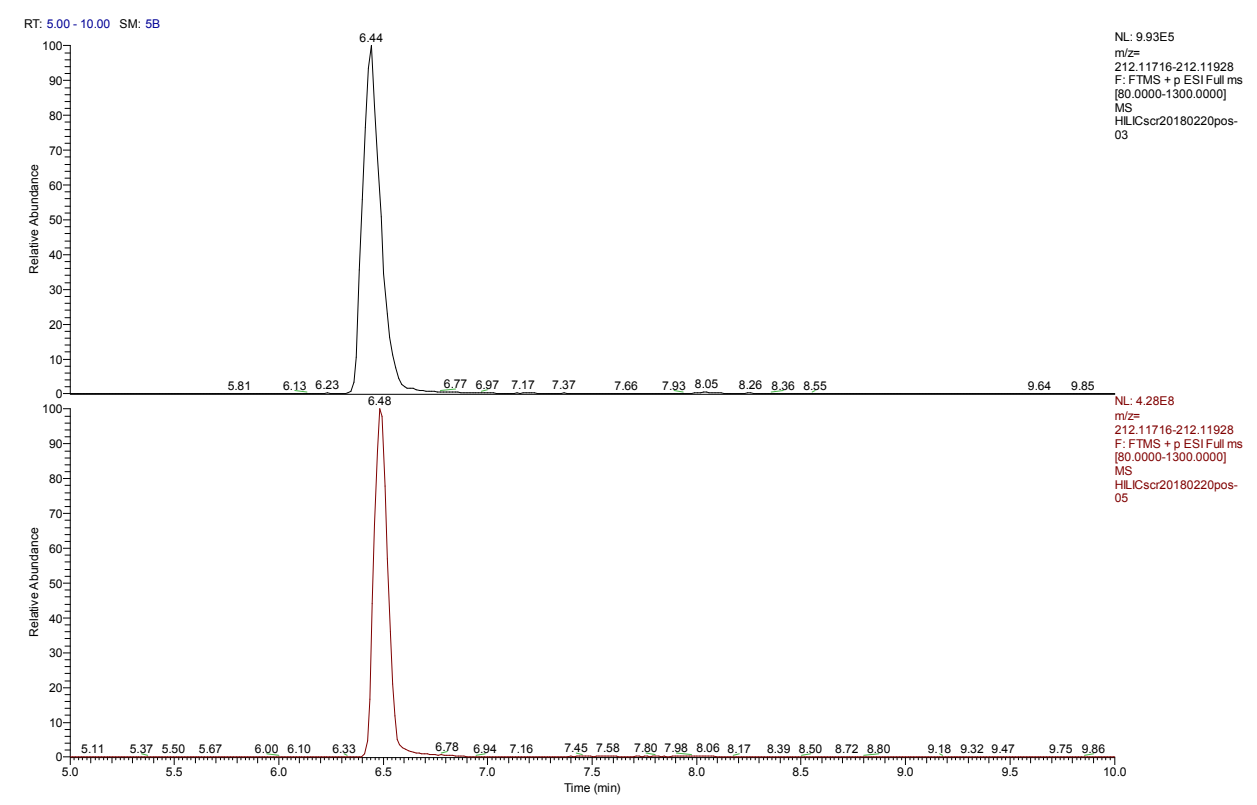

Accurate MS2-spectrum of $\mathrm{m} / \mathrm{z} 212.1182$ of the sample (upper panel) and the reference standard of N,N'-diphenylguanidine (resolution 15,000, CID CE $35 \%$ ):

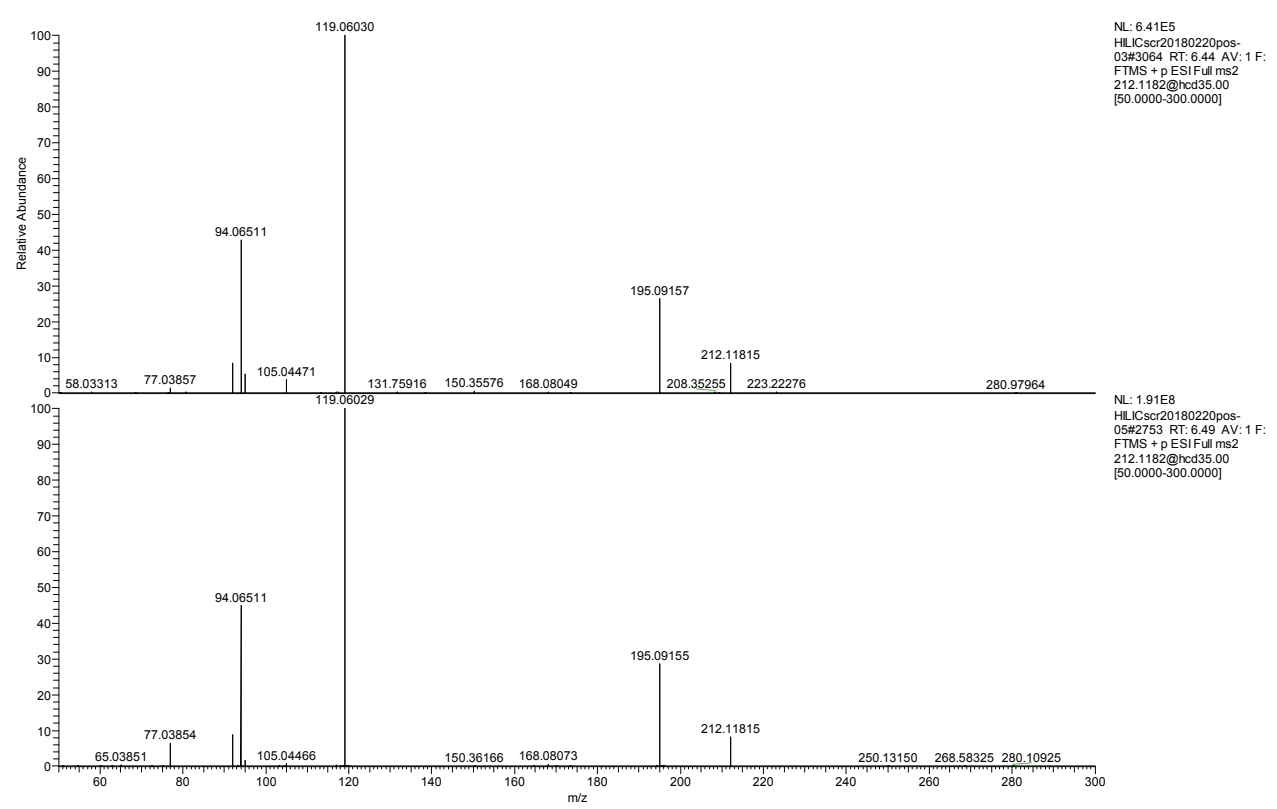




\section{Figure S4: Confirmation of the identity of metoprolol}

Extracted ion chromatogram ( $\mathrm{m} / \mathrm{z} 268.1907)$ of sample (upper panel) and reference standard (lower panel) of metoprolol:

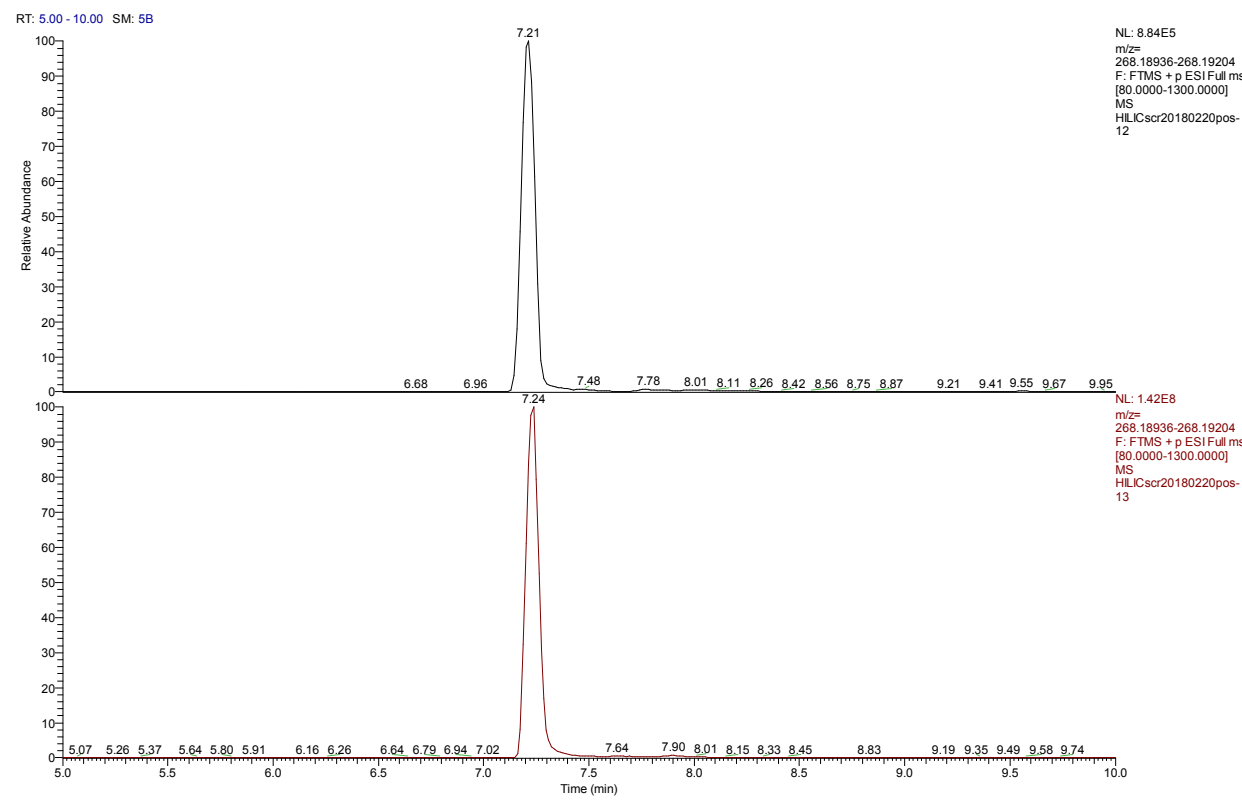

Accurate MS2-spectrum of $\mathrm{m} / \mathrm{z} 268.1907$ in the water sample (upper panel) and of the reference standard of metoprolol (resolution 15,000, CID CE $35 \%$ ):

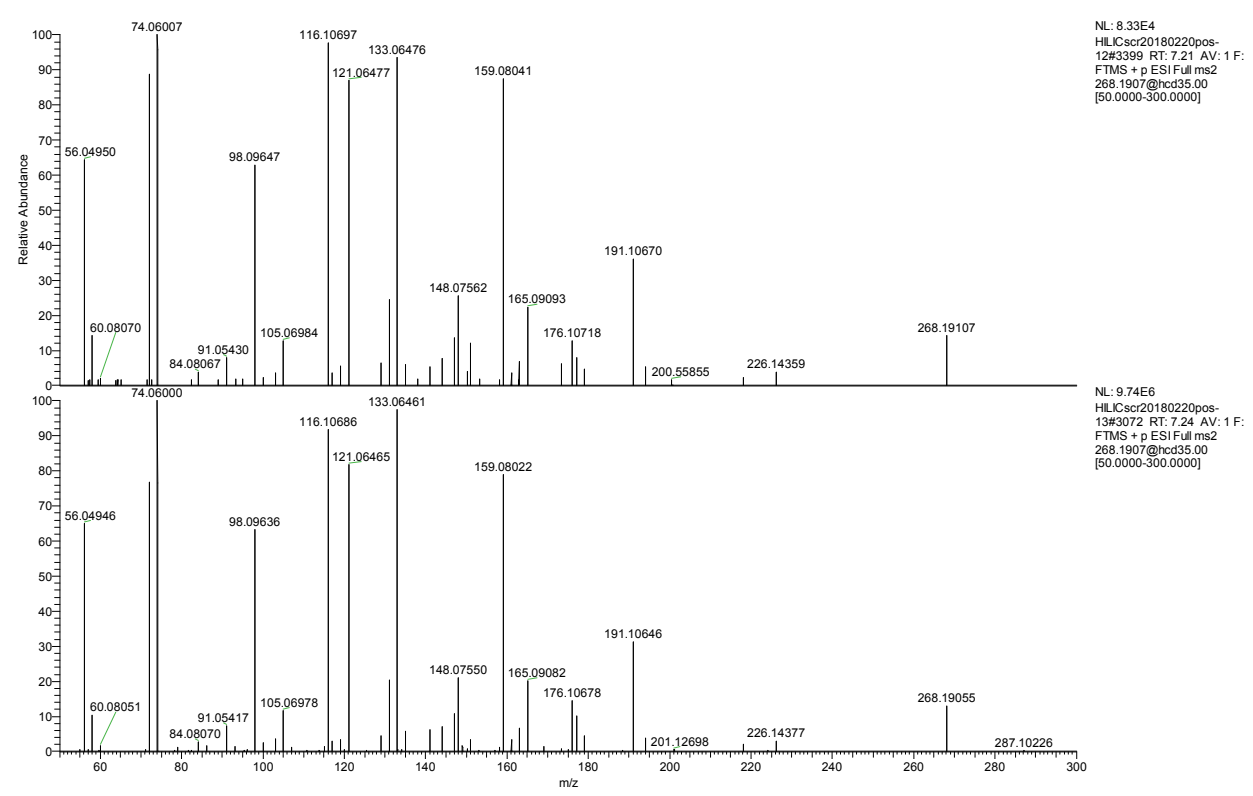




\section{Figure S5: Confirmation of the identity of (-)-nicotine}

Extracted ion chromatogram (m/z 163.1230)) of sample (upper panel) and reference standard (lower panel) of (-)-nicotine:

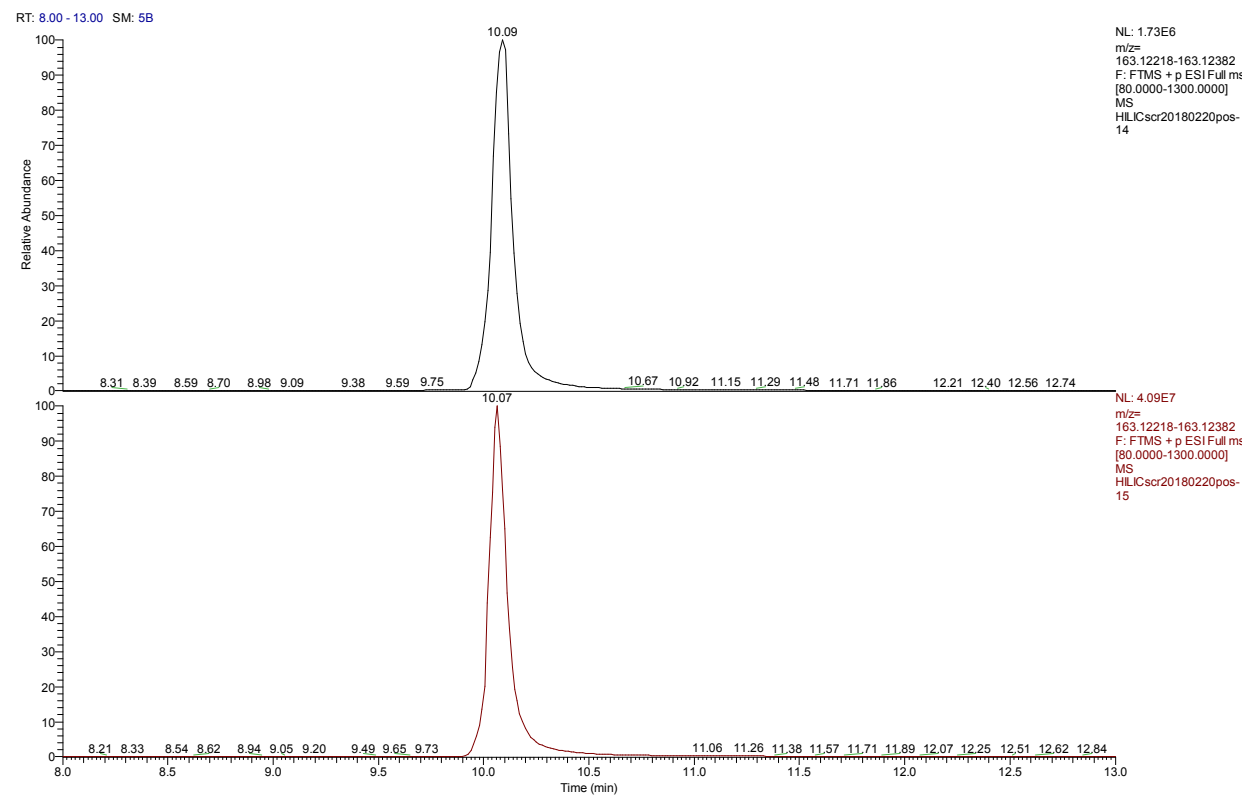

Accurate MS2-spectrum of $\mathrm{m} / \mathrm{z}$ 163.1230) in the water sample (upper panel) and of the reference standard of (-)-nicotine (resolution 15,000, CID CE $35 \%$ ):

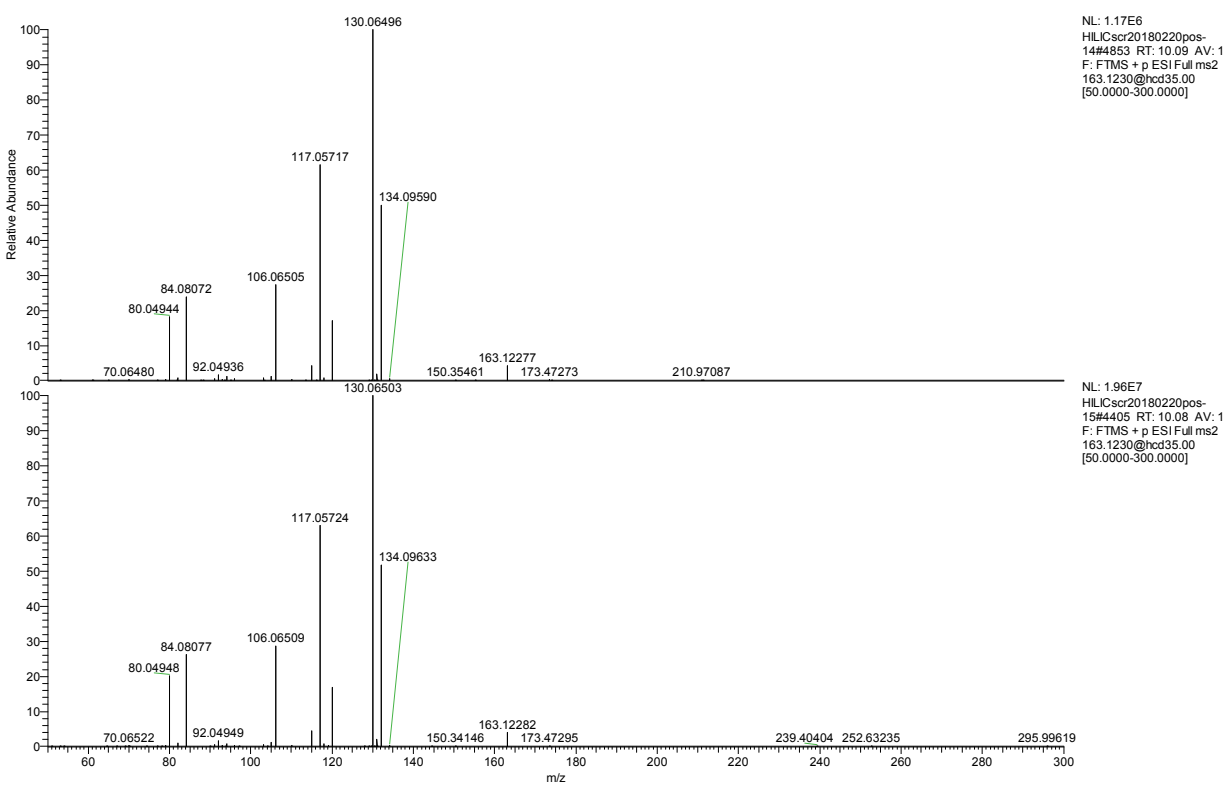




\section{Figure S6: Confirmation of the identity of guanine}

Extracted ion chromatogram (m/z 152.0567) of sample (upper panel) and reference standard (lower panel) of guanine:

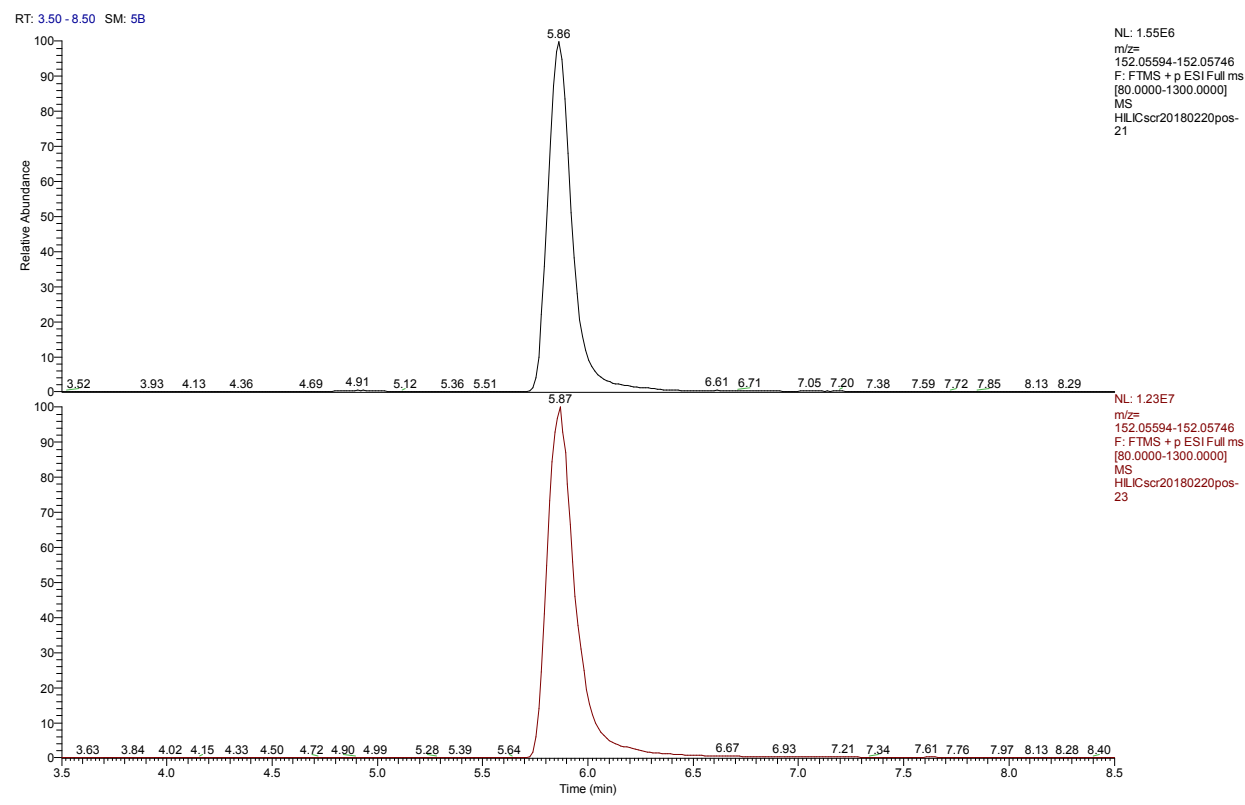

Accurate MS2-spectrum of $\mathrm{m} / \mathrm{z} 152.0567$ in the water sample (upper panel) and of the reference standard of guanine (resolution $15,000$, CID CE $35 \%)$ :

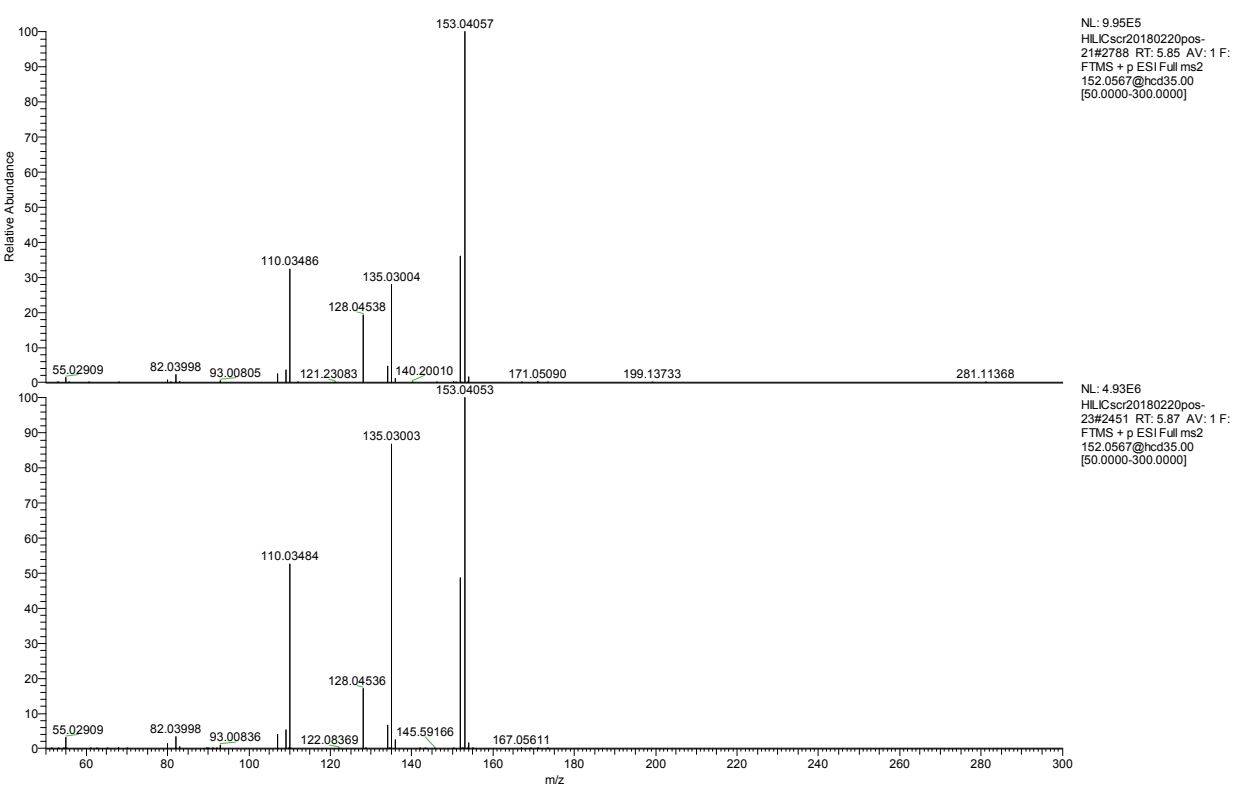




\section{Figure S7: Confirmation of the identity of choline}

Extracted ion chromatogram (m/z 104.1070) of sample (upper panel) and reference standard (lower panel) of choline:

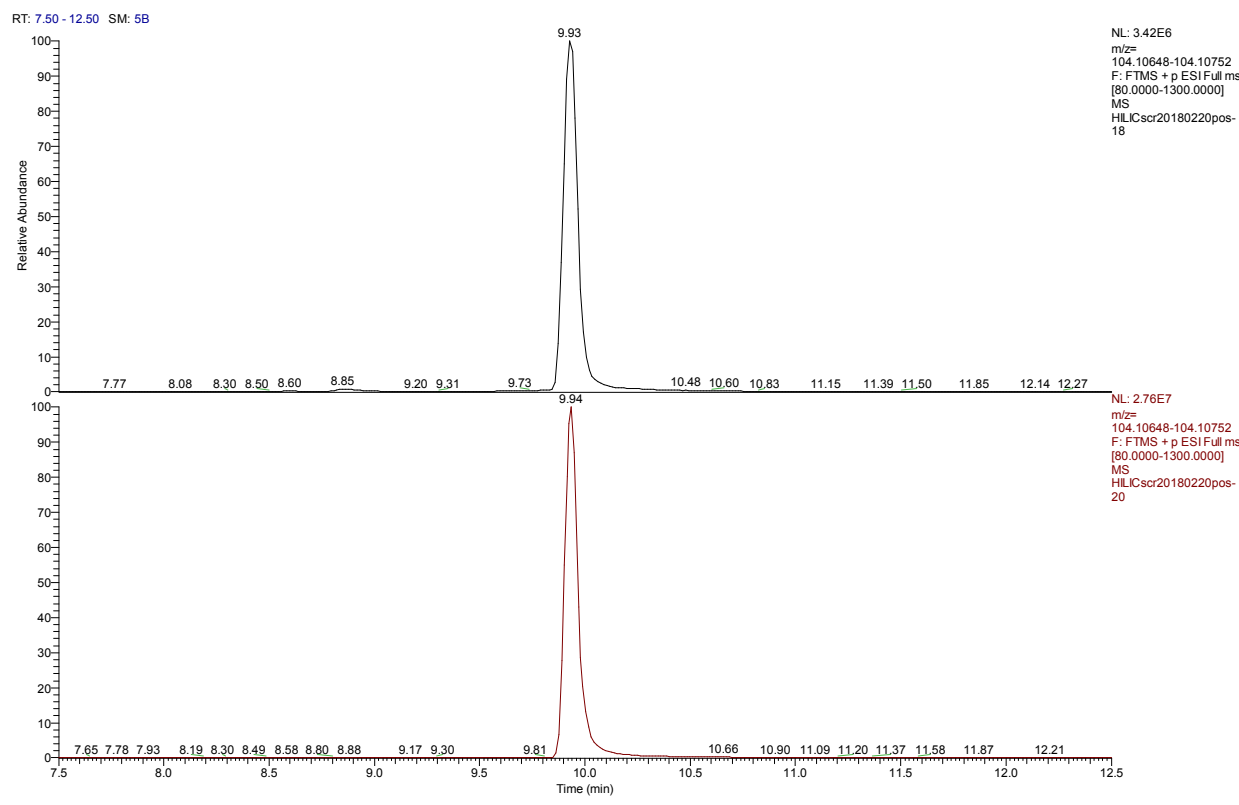

Accurate MS2-spectrum of $\mathrm{m} / \mathrm{z} 104.1070$ in the water sample (upper panel) and of the reference standard of choline (resolution $15,000$, CID CE $35 \%)$ :
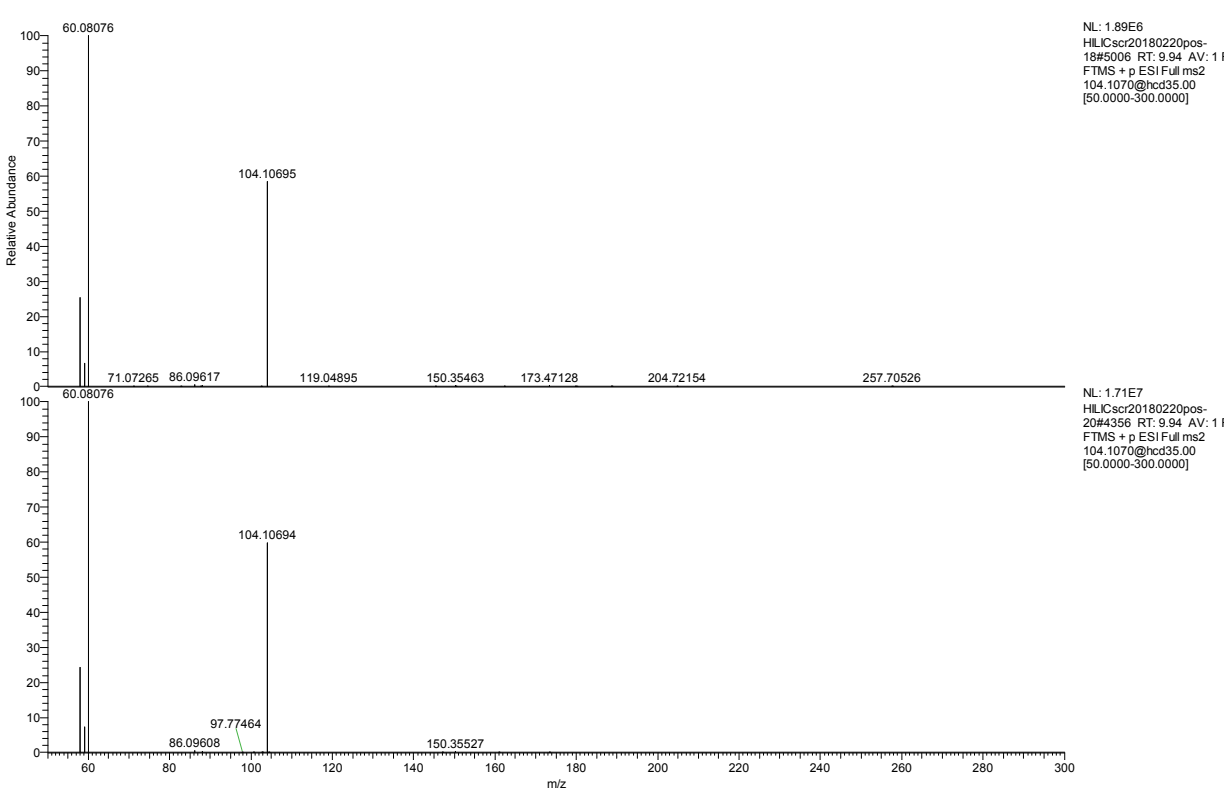

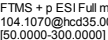

NL: $1.71 E 7$

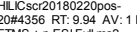

104.1070@hod 35.00
$50.0000-300.0000]$ 


\section{Figure S8: Confirmation of the identity of tramadol}

Extracted ion chromatogram ( $\mathrm{m} / \mathrm{z}$ 264.1958) of sample (upper panel) and reference standard (lower panel) of tramadol:

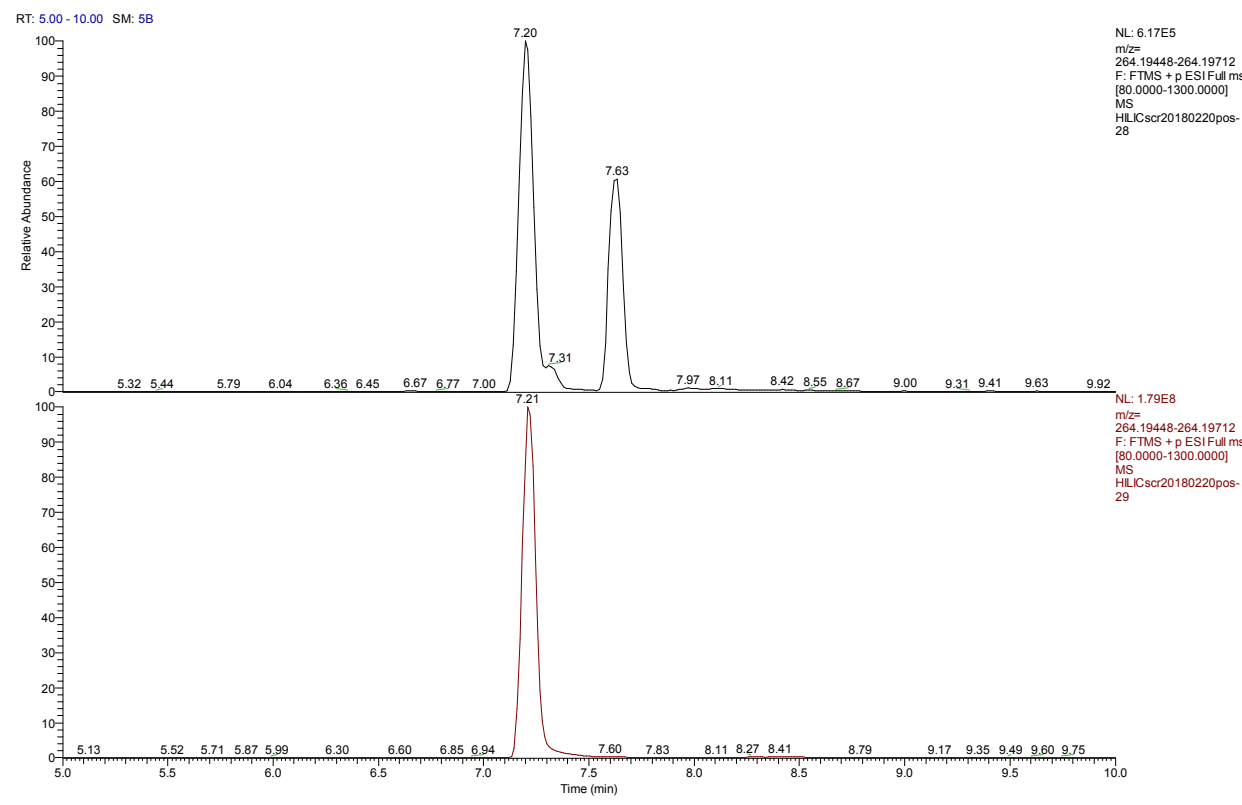

Accurate MS2-spectrum of $\mathrm{m} / \mathrm{z} 264.1958(\mathrm{rt}=7.2 \mathrm{~min}$ ) in the water sample (upper panel) and of the reference standard of tramadol (resolution 15,000, CID CE $35 \%$ ):

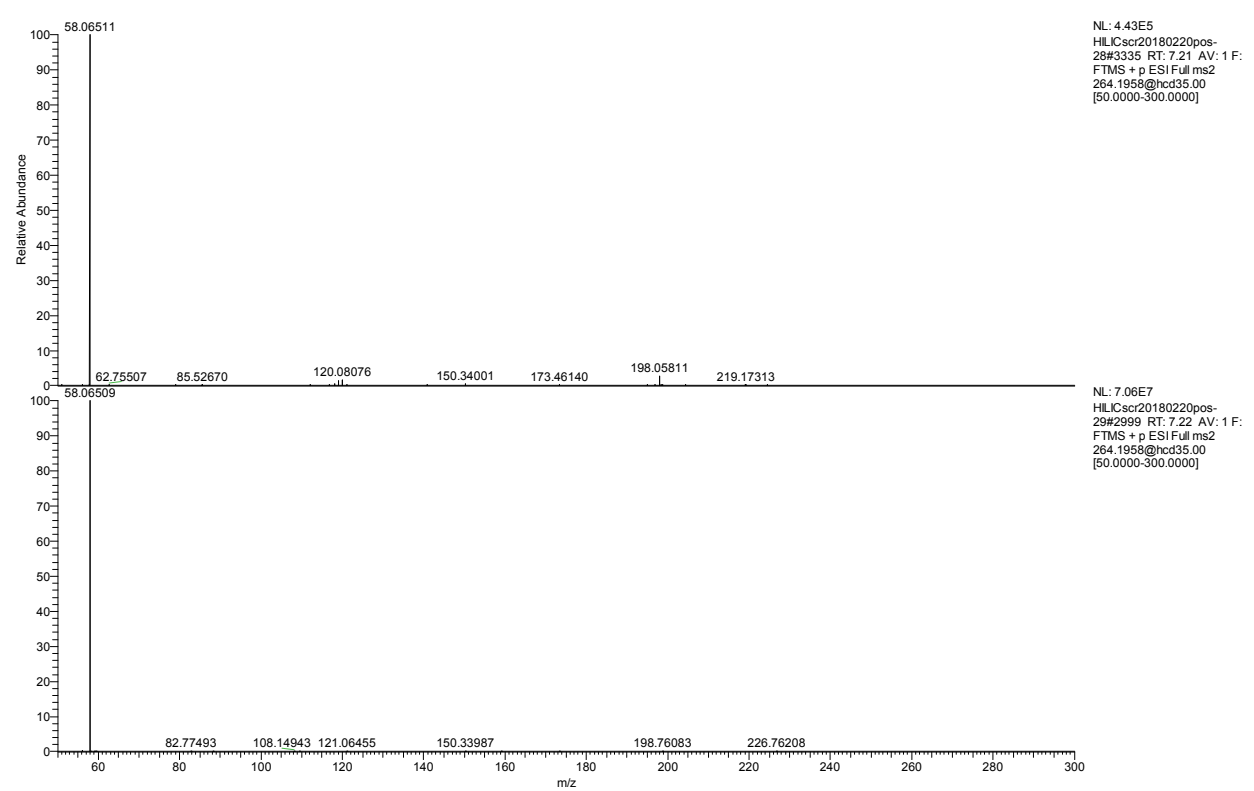




\section{Figure S9: Confirmation of the identity of triisopropanolamine}

Extracted ion chromatogram (m/z 192.1594) of sample (upper panel) and reference standard (lower panel) of triisopropanolamine:

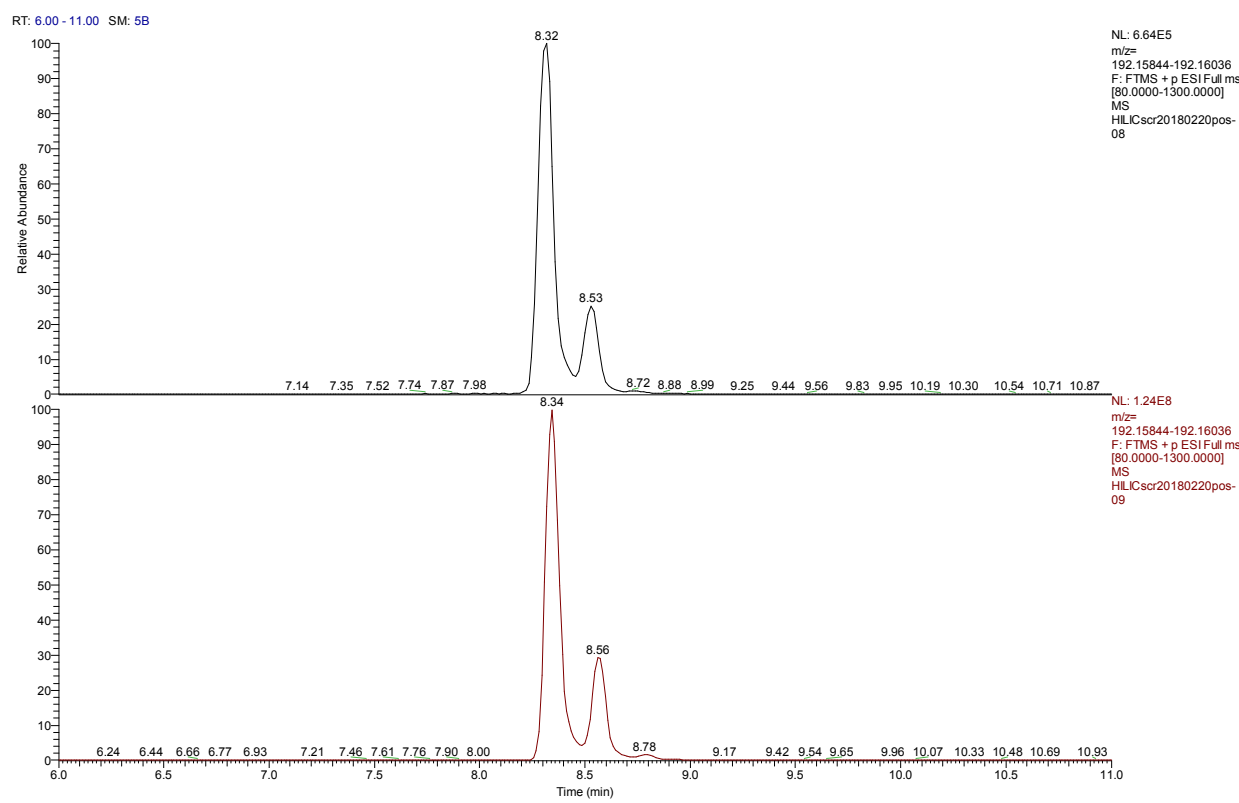

Accurate MS2-spectrum of $\mathrm{m} / \mathrm{z} 192.1594$ ( $\mathrm{rt}=8.3 \mathrm{~min}$ ) in the water sample (upper panel) and of the reference standard of triisopropanolamine (resolution 15,000, CID CE $35 \%$ ):

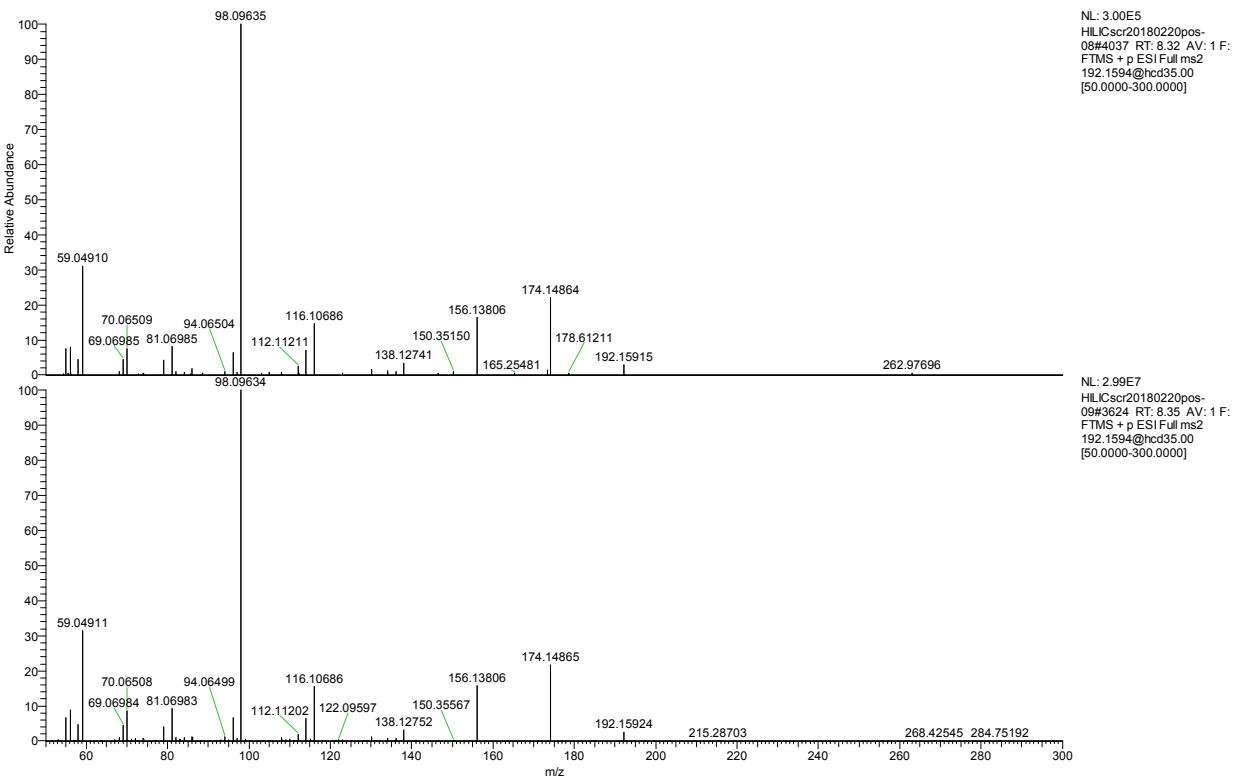




\section{Figure S10: Confirmation of the identity of phenazone}

Extracted ion chromatogram (m/z 189.1022) of sample (upper panel) and reference standard (lower panel) of phenazone:

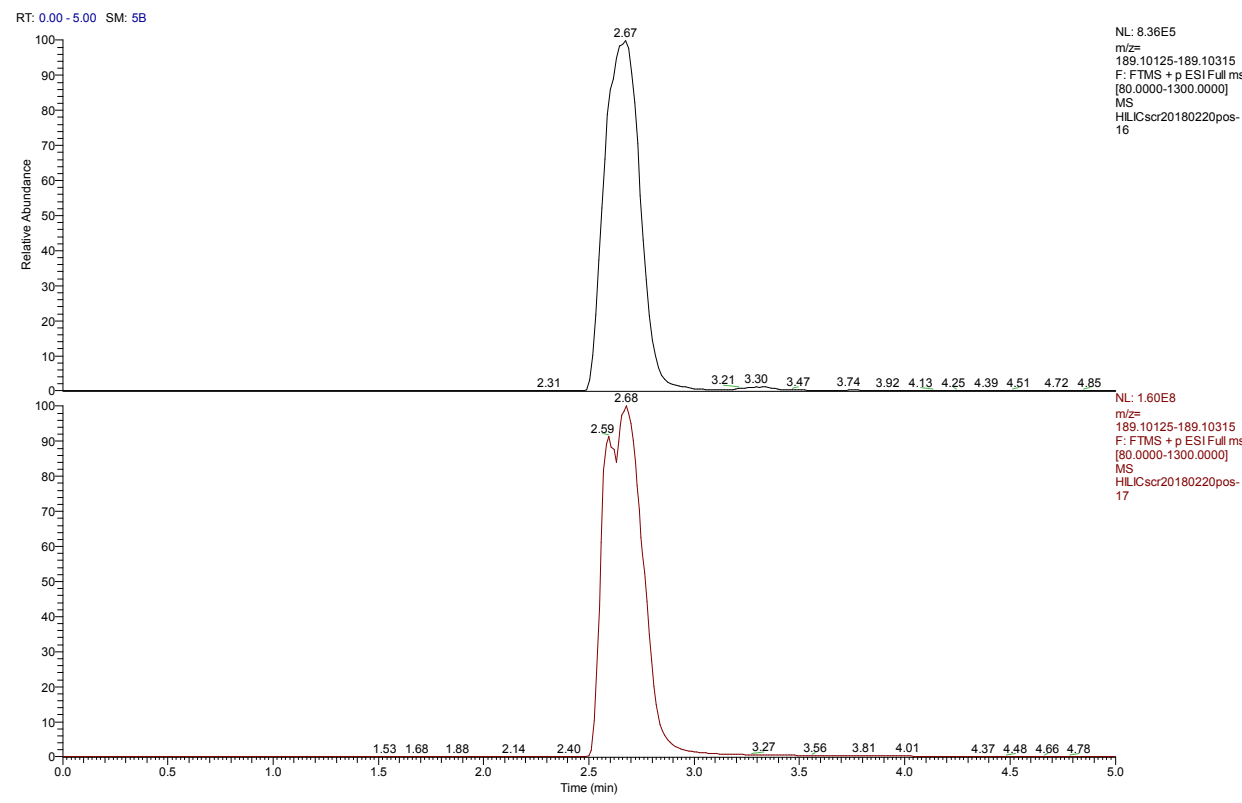

Accurate MS2-spectrum of $\mathrm{m} / \mathrm{z} 189.1022$ in the water sample (upper panel) and of the reference standard of phenazone (resolution 15,000, CID CE $35 \%$ ):

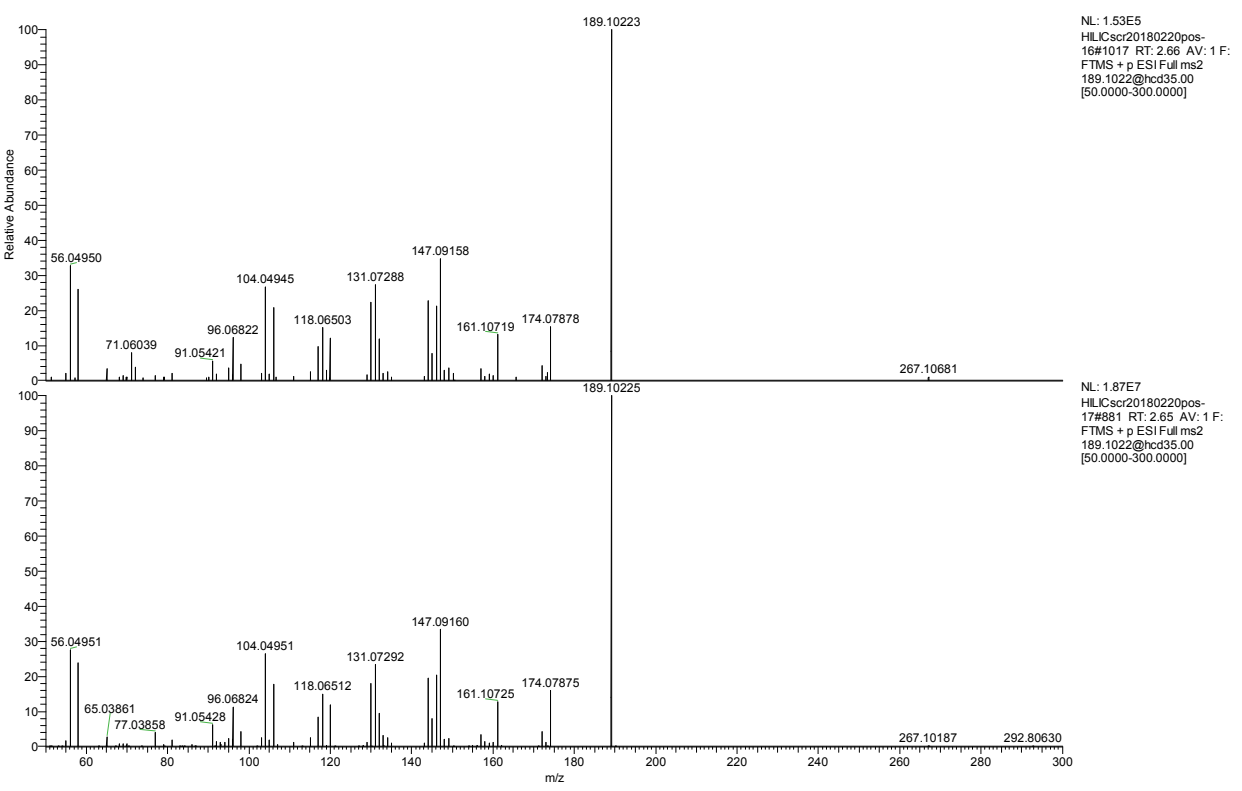




\section{Figure S11: No confirmation of the identity of 1,3-di-o-tolylguanidine}

Extracted ion chromatogram ( $\mathrm{m} / \mathrm{z} 240.1493)$ of sample (upper panel) and reference standard (lower panel) of 1,3-di-otolylguanidine:

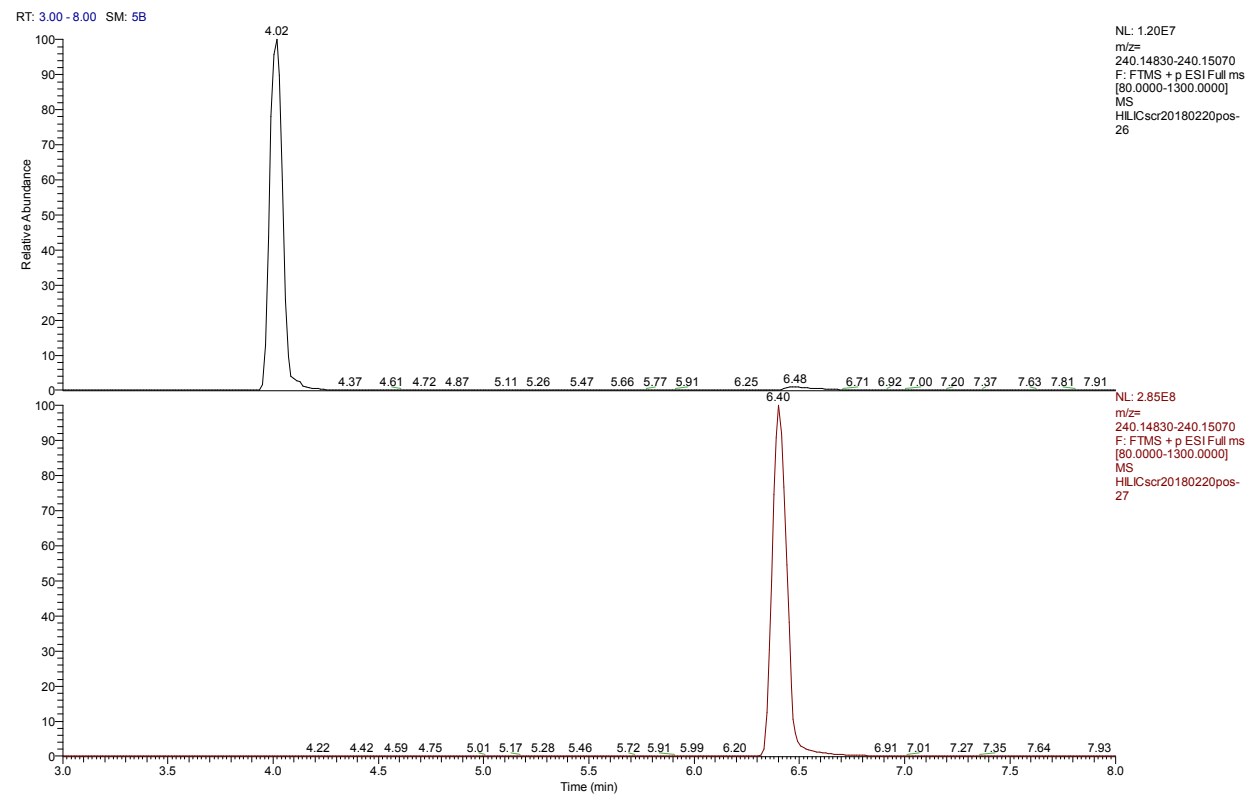

Accurate MS2-spectrum of m/z 240.1493 in the water sample (upper panel) and of the reference standard of 1,3-di-otolylguanidine (resolution 15,000, CID CE $35 \%$ ):

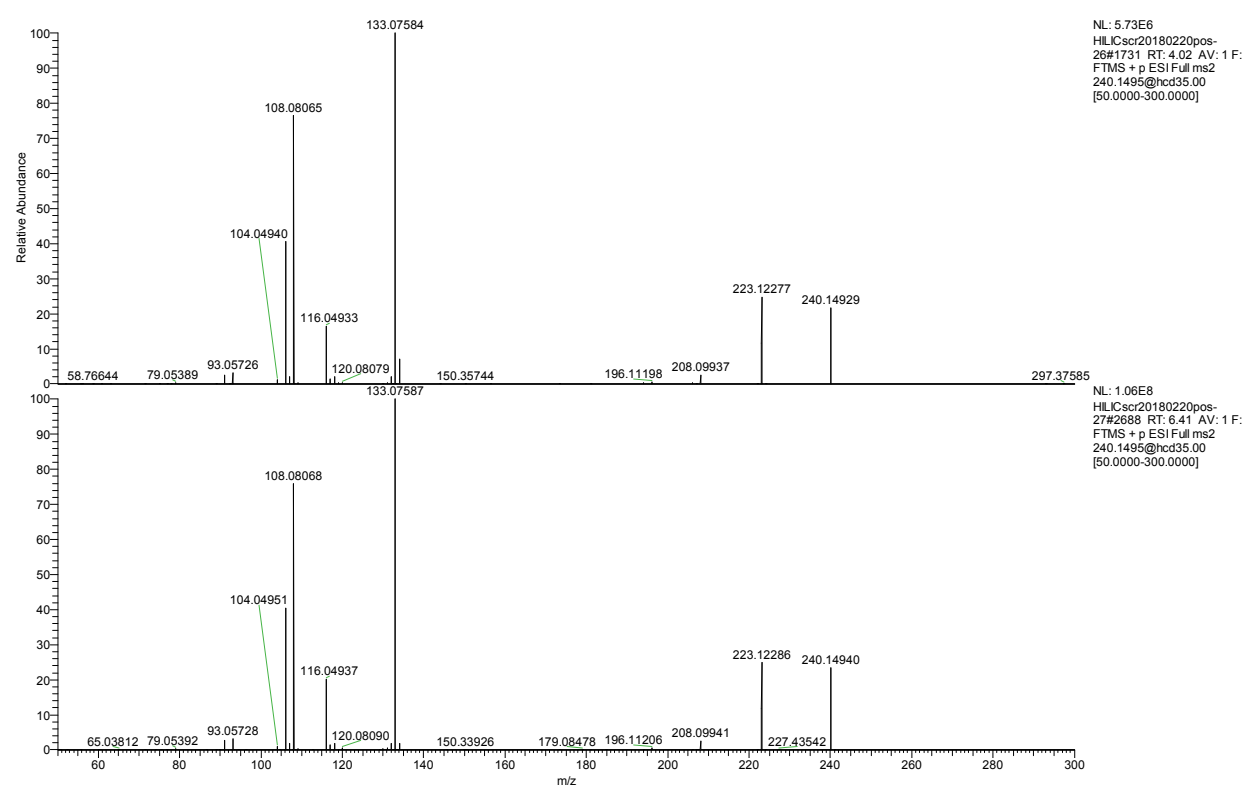




\section{Figure S12: Confirmation of the identity of o-desmethylvenlafaxine}

Extracted ion chromatogram ( $\mathrm{m} / \mathrm{z}$ 264.1958) of sample (upper panel) and reference standard (lower panel) of odesmethylvenlafaxine:

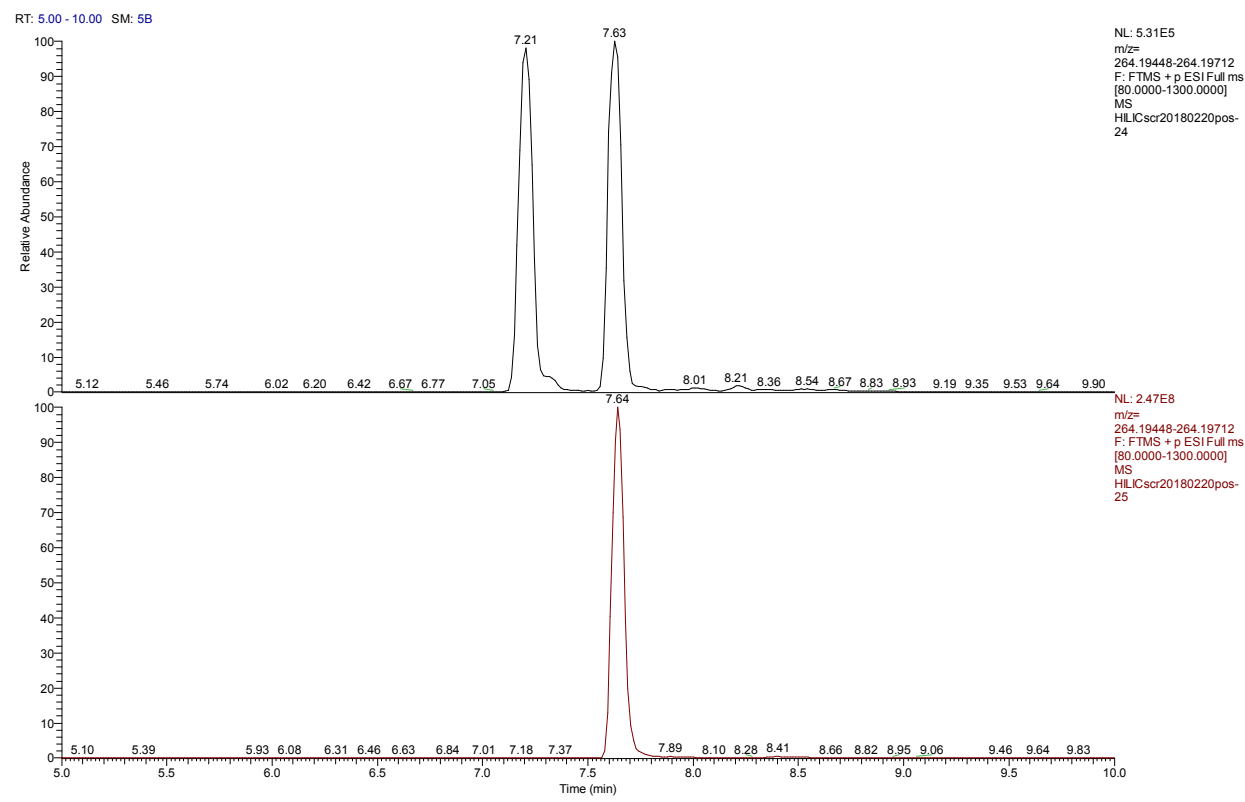

Accurate MS2-spectrum of $\mathrm{m} / \mathrm{z} 264.1958$ in the water sample (upper panel) and of the reference standard of odesmethylvenlafaxine (resolution 15,000, CID CE $35 \%$ ):
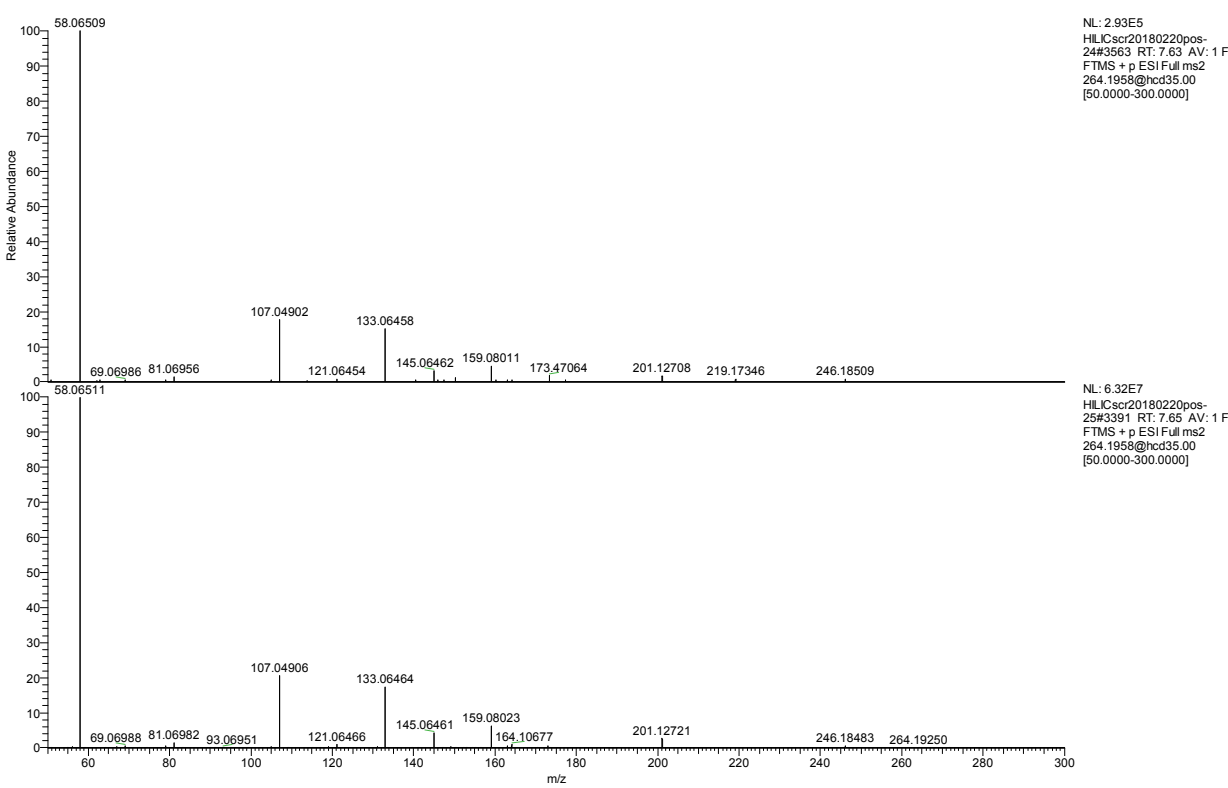


\section{Figure S13: Confirmation of the identity of triethanolamine}

Extracted ion chromatogram (m/z 150.1125) of sample (upper panel) and reference standard (lower panel) of triethanolamine:

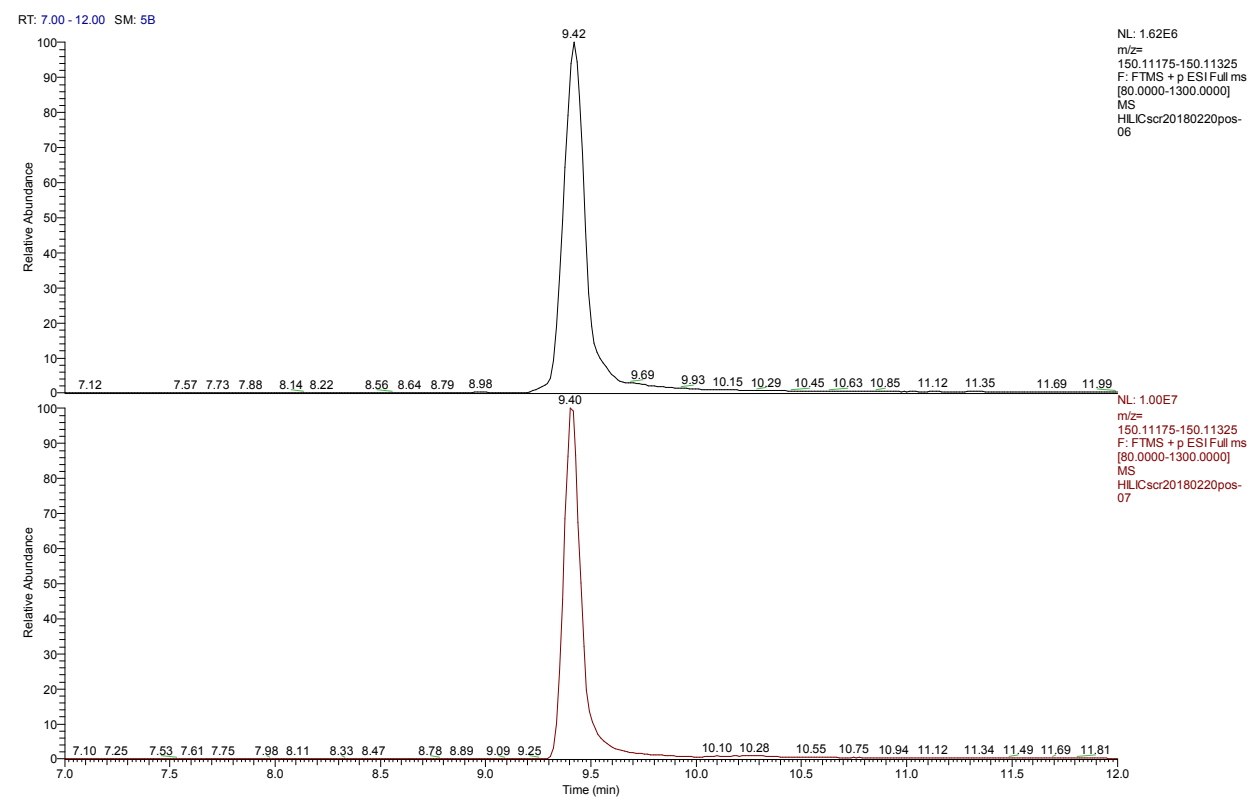

Accurate MS2-spectrum of $\mathrm{m} / \mathrm{z} 150.1125$ in the water sample (upper panel) and of the reference standard of triethanolamine (resolution 15,000, CID CE $35 \%$ ):

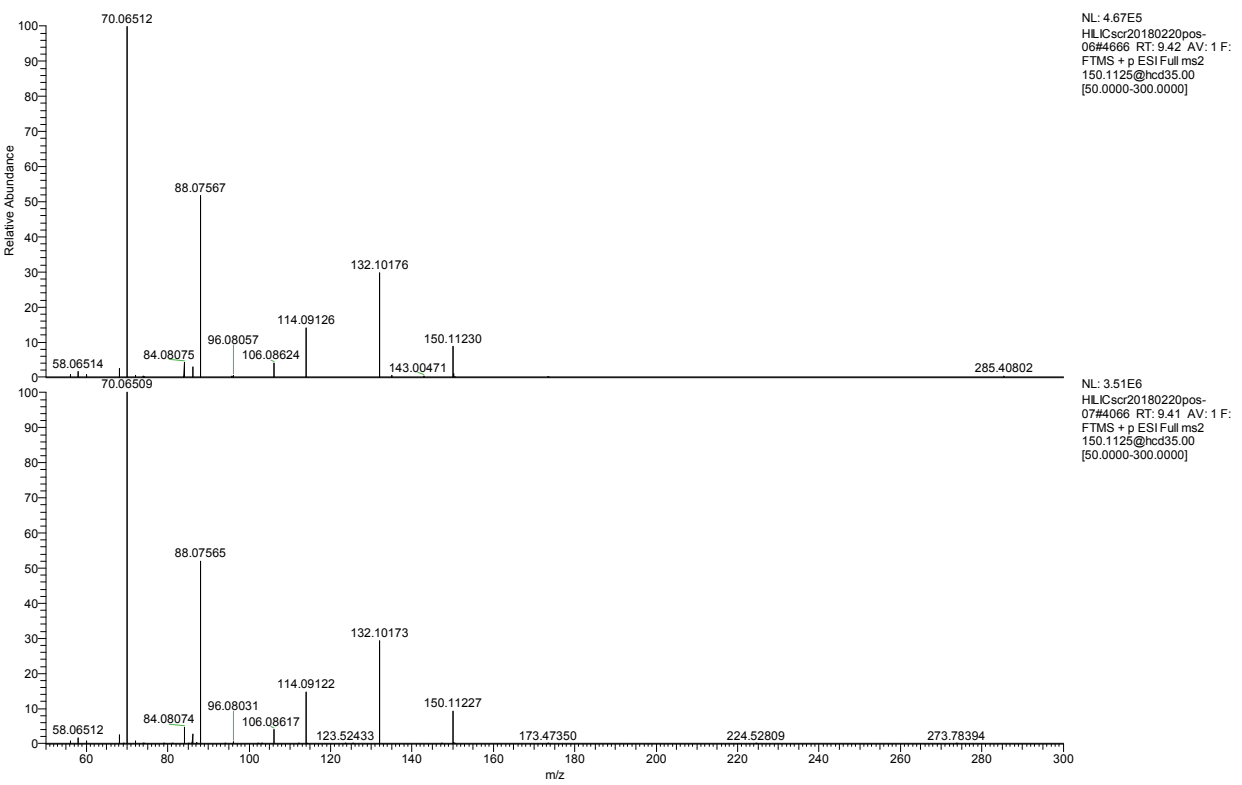




\section{Figure S14: Confirmation of the identity of 2,2,6,6-tetramethyl-4-piperidinol}

Extracted ion chromatogram ( $\mathrm{m} / \mathrm{z}$ 158.1539) of sample (upper panel) and reference standard (lower panel) of 2,2,6,6-tetramethyl4-piperidinol:

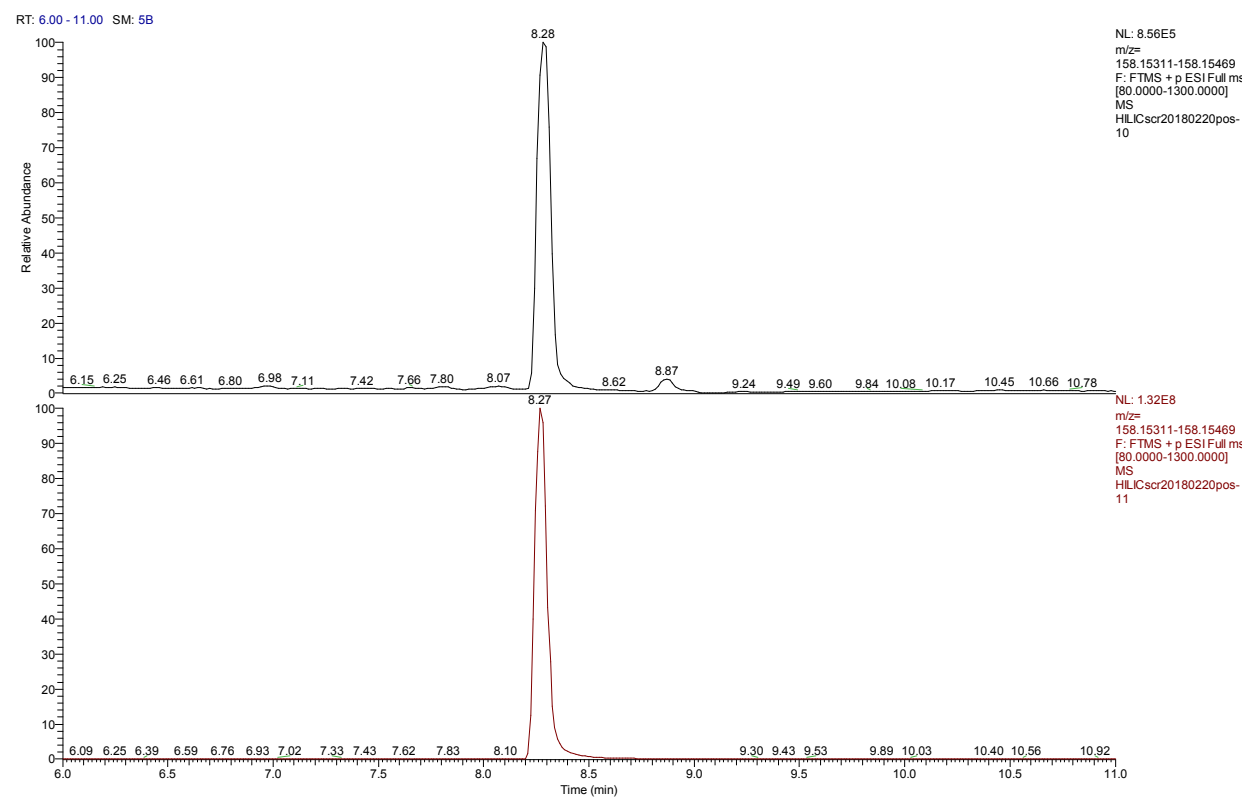

Accurate MS2-spectrum of $\mathrm{m} / \mathrm{z} 158.1539$ in the water sample (upper panel) and of the reference standard of 2,2,6,6-tetramethyl4-piperidinol (resolution 15,000, CID CE $35 \%$ ):
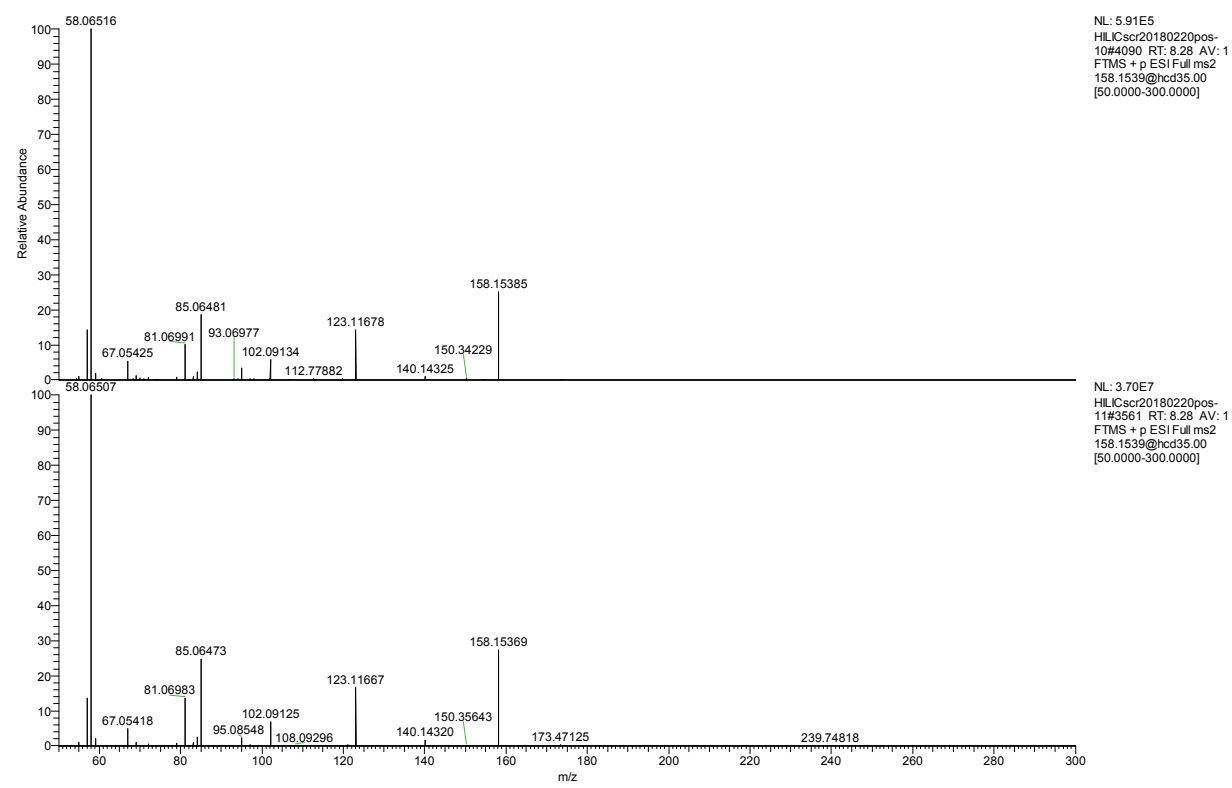

TMS + p ESIF III I Is: 1

[5. $0.1539 @ 000$-300.00000] 
Processing node 1: Select Spectra

1. General Settings:

- Precursor Selection: Use MS( $n$ - 1) Precursor

- Use New Precursor Reevaluation: True

- Use Isotope Pattern in Precursor Reevaluation: True

- Store Chromatograms: False

2. Spectrum Properties Filter:

- Lower RT Limit: 2.5

- Upper RT Limit: 0

- First Scan: 0

- Last Scan: 0

- Ignore Specified Scans: (not specified)

- Lowest Charge State: 0

- Highest Charge State: 0

- Min. Precursor Mass: 80 Da

- Max. Precursor Mass: 5000 Da

- Total Intensity Threshold: 0

- Minimum Peak Count: 1

3. Scan Event Filters:

- Mass Analyzer: (not specified)

- MS Order: Any

- Activation Type: (not specified)

- Min. Collision Energy: 0

- Max. Collision Energy: 1000

- Scan Type: Any

- Polarity Mode: (not specified)

4. Peak Filters:

- S/N Threshold (FT-only): 1.5

5. Replacements for Unrecognized Properties:

- Unrecognized Charge Replacements: 1

- Unrecognized Mass Analyzer Replacements: ITMS

- Unrecognized MS Order Replacements: MS2

- Unrecognized Activation Type Replacements: CID

- Unrecognized Polarity Replacements: +

- Unrecognized MS Resolution@200 Replacements: 60000

- Unrecognized MSn Resolution@200 Replacements: 30000

Processing node 2: Align Retention Times

1. General Settings:

- Alignment Model: Adaptive curve

- Alignment Fallback: Use Linear Model

- Maximum Shift [min]: 0.5

- Shift Reference File: True

- Mass Tolerance: 5 ppm

- Remove Outlier: True 


\section{Processing node 3: Detect Unknown Compounds}

1. General Settings:

- Mass Tolerance [ppm]: 5 ppm

- Intensity Tolerance [\%]: 30

- S/N Threshold: 10

- Min. Peak Intensity: 1000000

- lons:

$$
\begin{aligned}
& {[2 \mathrm{M}+\mathrm{H}]+1} \\
& {[\mathrm{M}+2 \mathrm{H}]+2} \\
& {[\mathrm{M}+\mathrm{ACN}+\mathrm{H}]+1} \\
& {[\mathrm{M}+\mathrm{H}]+1} \\
& {[\mathrm{M}+\mathrm{H}-\mathrm{H} 2 \mathrm{O}]+1} \\
& {[\mathrm{M}+\mathrm{K}]+1} \\
& {[\mathrm{M}+\mathrm{Na}]+1} \\
& {[\mathrm{M}+\mathrm{NH} 4]+1}
\end{aligned}
$$

- Base lons: $[\mathrm{M}+\mathrm{H}]+1$; $[\mathrm{M}-\mathrm{H}]-1$

- Min. Element Counts: C H

- Max. Element Counts: C90 H190 Br3 Cl4 K2 N10 Na2 O15 P2 S5

2. Peak Detection:

- Filter Peaks: True

- Max. Peak Width [min]: 0.8

- Remove Singlets: True

- Min. \# Scans per Peak: 5

- Min. \# Isotopes: 1

Processing node 4: Group Unknown Compounds

1. Compound Consolidation:

- Mass Tolerance: 5 ppm

- RT Tolerance [min]: 0.1

2. Fragment Data Selection:

- Preferred lons: $[\mathrm{M}+\mathrm{H}]+1 ;[\mathrm{M}-\mathrm{H}]-1$

Processing node 7: Fill Gaps

1. General Settings:

- Mass Tolerance: 5 ppm

- S/N Threshold: 1.5

- Use Real Peak Detection: True

Processing node 5: Mark Background Compounds

1. General Settings:

- Max. Sample/Blank: 5

- Max. Blank/Sample: 0

- Hide Background: False 
Processing node 20: Search mzCloud

1. Search Settings:

- Compound Classes: All

- Match Ion Activation Type: True

- Match Ion Activation Energy: Match with Tolerance

- Ion Activation Energy Tolerance: 20

- Apply Intensity Threshold: True

- Precursor Mass Tolerance: 10 ppm

- FT Fragment Mass Tolerance: 0.0025 Da

- IT Fragment Mass Tolerance: 0.4 Da

- Identity Search: HighChem HighRes

- Similarity Search: None

- Library: Reference

- Post Processing: Recalibrated

- Match Factor Threshold: 20

- Max. \# Results: 10

Processing node 21: Pattern Scoring

1. General Settings:

- Isotope Patterns: Cl; Cl2; $\mathrm{Br} ; \mathrm{Br} 2 ; \mathrm{Cl} 3$

- Mass Tolerance: 5 ppm

- Intensity Tolerance [\%]: 30

- SN Threshold: 10

- Min. Spectral Fit [\%]: 0

Processing node 6: Predict Compositions

1. Prediction Settings:

- Mass Tolerance: 5 ppm

- Min. Element Counts: $\mathrm{C} \mathrm{H}$

- Max. Element Counts: C90 H190 Br3 Cl4 N10 O15 P2 S5

- Min. RDBE: -1

- Max. RDBE: 40

- Min. H/C: 0.1

- Max. H/C: 3

- Max. \# Candidates: 10

- Max. \# Internal Candidates: 200

2. Pattern Matching:

- Intensity Tolerance [\%]: 30

- Intensity Threshold [\%]: 0.1

- S/N Threshold: 3

- Min. Spectral Fit [\%]: 10

- Min. Pattern Cov. [\%]: 90

- Use Dynamic Recalibration: True

3. Fragments Matching:

- Use Fragments Matching: True

- Mass Tolerance: 5 ppm 
- S/N Threshold: 3

Processing node 23: Search Mass Lists

1. Search Settings:

- Input file(s): hilic.csv;extracompc18.csv

- Mass Tolerance: 5 ppm

- Show extra Fields as Columns: False

- Consider Retention Time: True

- RT Tolerance : 0.05

Processing node 26: Search ChemSpider

1. Search Settings:

- Mass Tolerance: 5 ppm

- Database(s): KEGG

- Max. \# of results per compound: 100

- Max. \# of Predicted Compositions to be searched per Compound: 3

- Result Order (for Max. \# of results per compound): Order By Reference Count (DESC)

2. Predicted Composition Annotation:

- Check All Predicted Compositions: False

Processing node 14: Merge Features

1. Peak Consolidation:

- Mass Tolerance: 5 ppm

- RT Tolerance [min]: 0.1

Processing node 15: Differential Analysis

1. General Settings:

- Log10 Transform Values: True

Processing node 24: Descriptive Statistics

No parameters

Processing node 25: Assign Compound Annotations

1. General Settings:

- Mass Tolerance: 5 ppm

2. Data Sources:

- Data Source \#1: mzCloud Search

- Data Source \#2: Predicted Compositions

- Data Source \#3: MassList Match

- Data Source \#4: ChemSpider Search 